\title{
CD4 and CD8 T cells mediate distinct lethal meningoencephalitis in mice challenged with Tacaribe arenavirus
}

\author{
Derek DC Ireland, Cecilia Tami, Joao Pedras-Vasconcelos and Daniela Verthelyi
}

Neonates are at increased risk of viral encephalopathies that can result in neurological dysfunction, seizures, permanent disability and even death. The neurological damage results from the combined effect of the virus and the immune response it elicits, thus finding tools to facilitate viral clearance from central nervous system (CNS) while minimizing neuron damage remains a critical challenge. Neonatal mice inoculated intraperitoneally with Tacaribe virus (TCRV) develop seizures, hindlimb paralysis and death within 15 days of inoculation. TCRV localizes to the CNS within days of challenge, primarily infecting astrocytes in the cerebellum and brain stem. We show that infection leads to inflammation, T cell and monocyte infiltration into the cerebellar parenchyma, apoptosis of astrocytes, neuronal degeneration and loss of Purkinje cells. Infiltrating antigen-specific $T$ cells fail to clear the virus but drive the disease, as T-cell-deficient CD3ع KO mice survive TCRV infection with minimal inflammation or clinical manifestations despite no difference in CNS viral loads in comparison with T-cell sufficient mice. CD8+ T cells drive the pathology, which even in the absence of CD4+ T-cell help, infiltrate the parenchyma and mediate the apoptotic loss of cerebellar astrocytes, neurodegeneration and loss of Purkinje cells resulting in loss of balance, paralysis and death. CD4+ T cells are also pathogenic inducing gliosis and inflammation in the cerebellum and cerebrum that are associated with wasting and death several weeks after CD4+ T-cell transfer. These data demonstrate distinct pathogenic effects of CD4+ and CD8+ T cells and identify them as possible therapeutic targets.

Cellular \& Molecular Immunology (2017) 14, 90-106; doi:10.1038/cmi.2016.41; published online 29 August 2016

Keywords: Astrocytes; CD4 T cells; CD8 T cells; encephalitis; Purkinje cells; virus

\section{INTRODUCTION}

New World arenaviruses (NWA) (Tacaribe serocomplex) are a growing family of enveloped segmented RNA viruses that include several highly pathogenic members: Junin, Machupo, Guanarito and Sabia viruses that cause hemorrhagic fevers in humans. ${ }^{1-3}$ If untreated, these viruses can cause severe hemorrhagic and neurological manifestations such as confusion, reduced reflexes, convulsions and coma, and have high mortality rates. ${ }^{4,5}$ As with most viral hemorrhagic fevers, current therapy for NWA consists primarily of convalescent sera and supportive care. Availability of immune plasma is limited and antiviral Ribavarin has been used with mixed efficacy and significant adverse responses. ${ }^{4}$ Recent efforts focus on the use of monoclonal antibodies either to reduce the inflammation or to neutralize the virus. ${ }^{6,7}$ Neurological symptoms are more common with NWA than with Old World arenavirus infections and about $10 \%$ of patients who survive acute infection with NWA develop long-lasting neurological sequelae. ${ }^{2,3,5}$ Given their high pathogenic potential, human to human transmission, ease of growth in culture, plastic genomic structure and lack of proven effective therapeutic approaches, these viruses have been included in the list of Class 1A potential biowarfare agents by the United States Centers for Disease Control. ${ }^{5}$ Improved understanding of the interactions of these viruses with their host, particularly in the CNS, may help design new and more effective treatments for new NWA that protect the nervous system.

Tacaribe virus (TCRV), a member of the Clade B of NWA, is closely related to Junin, the etiologic agent of Argentine hemorrhagic fever, ${ }^{8}$ but has a lower pathogenic potential for

Division of Biologics Review and Research-III, Office of Biotechnology, Center for Drug Evaluation and Research, Food and Drug Administration, Silver Spring, MD 20993, USA

Correspondence: Dr D Verthelyi, MD, PhD, Division of Biologics Review and Research-III, Office of Biotechnology, Center for Drug Evaluation and Research Food and Drug Administration, Building 52-Room 2112, 10903 New Hampshire Ave., Silver Spring, MD 20993, USA.

E-mail: daniela.verthelyi@fda.hhs.gov

Received: 29 March 2016; Revised: 15 June 2016; Accepted: 17 June 2016 
humans and is therefore more easily amenable to laboratory study. ${ }^{9,10}$ TCRV infects neonatal, but not adult, mice. Following an intraperitoneal (i.p.) challenge, TCRV is only found in the central nervous system (CNS) and is not detectable in peripheral organs 6 days post infection (dpi). ${ }^{6}$ The virus localizes primarily to the brain stem and cerebellum, leading to the development of a lethal meningoencephalitis characterized by diminished activity, flaccid hindlimb paralysis, tremors and death 10-15 dpi. ${ }^{11,12}$ TCRV is non-cytolytic and the associated neuropathology is a direct result of the immune response it elicits. ${ }^{6} 11$ This provides a clear model for assessing the contribution of individual immune cell types to pathogenicity during infection. Previous studies showed that blocking tumor necrosis factor alpha (TNF- $\alpha$ ) improved survival significantly $(100 \%)$, despite persisting infection, indicating that the inflammatory process in the CNS is critical to the development of disease. ${ }^{6}$ Importantly, mice lacking $\mathrm{T}$ cells (thymectomized before day 3 of life, nude ${ }^{n u / n u}$ or RAG $^{n u / n u}$ ) survive TCRV infection despite high titers of virus in the CNS. ${ }^{6,11}$ This indicates that $\mathrm{T}$ cells play an important role in pathogenesis although these cells cannot be infected by the virus. ${ }^{11,13-15}$ Currently the role of $\mathrm{T}$ cells in the CNS is an area of intense study, but their precise roles in the context of viral encephalopathy are not fully understood. Recent studies proposing the use of adoptive transfer with antiviral $\mathrm{T}$ cells as a possible treatment to clear microglia persistently infected with Old World Clade arenavirus lymphocytic choriomeningitis virus (LCMV) underscore the need to understand the role of $\mathrm{T}$ cells in viral meningoencephalitis. ${ }^{16}$

This study examines the role that $\mathrm{CD} 4+$ and $\mathrm{CD} 8+\mathrm{T}$-cell subsets play in the pathogenesis of TCRV-infected neonatal animals, utilizing $\mathrm{CD} 3 \varepsilon$-deficient $(\mathrm{CD} 3 \varepsilon \mathrm{KO})$ mice. These mice develop normal thymic architecture, but fail to develop T cells beyond the double-negative stage 3 (DN3) of development (CD3-positive, CD4, CD8 double-negative (CD44-/CD25+) stage ${ }^{17}$ resulting in a mouse completely deficient in mature $\mathrm{T}$ cells. We show here that infected CD3e KO mice develop a mild inflammation in the CNS but fail to develop disease despite harboring viral titers in the CNS comparable to those of WT control animals. Passive transfer of naïve or memoryenriched (convalescent) total splenic T cells into infected CD3E $\mathrm{KO}$ animals leads to the development of a fatal encephalitis similar to that of infected wild-type animals, confirming the role of $\mathrm{T}$ cells in disease. Importantly, while both CD8+ and $\mathrm{CD} 4+\mathrm{T}$ cells independently infiltrate the parenchyma and cause CNS inflammation resulting in encephalopathy and death, recipients of the different T-cell sub-types differ significantly in their clinical course and underlying pathology. Improved understanding of the role of $\mathrm{T}$ cells may help identify therapeutic targets that reduce neurological sequelae of hemorrhagic fevers.

\section{MATERIALS AND METHODS}

\section{Mice}

C57BL/6, C57BL/6 $\mathrm{CD} 3 \varepsilon-1-$ and C57BL/6-OT-1-Tg mice used in this study were bred as homozygous breeding pairs $(>20$ generations). C57BL/6 $\mathrm{CD} 3 \varepsilon-1-(\mathrm{CD} 3 \varepsilon \mathrm{KO})$ were generously provided by Elizabeth Shores (Division of Therapeutic Proteins, FDA, retired). Mice were housed in sterile microisolator cages under $12 \mathrm{~h}$ day/night cycle and given food and water ad libitum in the specific pathogen-free, AAALAC accredited animal facility of the U.S. Food and Drug Administration's Center for Biologics Evaluation and Research (Bethesda, MD, USA and Silver Spring, MD, USA). All animals and experimental protocols were reviewed and approved by the Center for Biologics Evaluation and Research Institutional Animal Care and Use Committee (IACUC).

\section{Virus preparation-TCRV}

TCRV strain TRVL 11573 was obtained from American Type Culture Collection (ATCC, Manassas, VA, USA) as a suckling mouse brain desiccate and prepared as previously described. ${ }^{12}$ Briefly, TCRV was resuspended in $1 \mathrm{ml}$ of water and subjected to three subsequent passages on Vero (African green monkey kidney fibroblast-like; ATCC) cell monolayers, each for 7 days at $37^{\circ} \mathrm{C}$. Vero cells were grown in monolayers in Earl's minimum essential (EMEM; ThermoFisher, Carlsbad, CA, USA) media supplemented with $5 \%$ fetal bovine serum and $2 \mathrm{~mm}$ L-glutamine (ThermoFisher). After each passage, cells and supernatants were frozen and thawed to lyse cells, releasing virus. Cellular debris was pelleted at $500 \mathrm{~g}$ for $15 \mathrm{~min}$ and viruscontaining supernatants were stored at $-80^{\circ} \mathrm{C}$. Supernatants obtained from the third infection passage were titrated by endpoint dilution $\left(\mathrm{TCID}_{50}\right)$ assay on Vero cells monolayers in 96well plates (see the section Virus quantification).

\section{TCRV infections}

All newborn mice were born from pathogen-free parents and inoculated with $2000 \times \mathrm{TCID}_{50}$ of TCRV in $20 \mu \mathrm{l}$ of EMEM by intraperitoneal injection, three days after birth (P3) as previously described. ${ }^{5,12}$ Convalescent mice used to generate T cells were inoculated with $2000 \times \mathrm{TCID}_{50}$ on P7-P10 and boosted with an equivalent dose of TCRV 7 days before harvesting spleens. Age-matched, uninfected mice were used as control animals for all studies. For experiments tracking survival following TCRV infection, mice were monitored daily for indications of pathology. Moribund (unable to access nutrition due to severe paresis and/or respiratory distress) animals were killed in accordance with the IACUC guidelines.

\section{Virus quantification}

For brain homogenates, infected mice were killed by $\mathrm{CO}_{2}$ asphyxiation and exsanguinated by transcardiac perfusion. Brains were removed aseptically, placed in $2 \mathrm{ml}$ of cold Roswell Park Memorial Institute (RPMI) media (ThermoFisher) and manually disrupted with ice-cold Tenbroeck glass grinders (Wheaton, Millville, NJ, USA) until uniform homogenates were obtained. The cellular fractions were pelleted by centrifugation at $400 \mathrm{~g}$ for $15 \mathrm{~min}$. The supernatants were collected and stored at $-80^{\circ} \mathrm{C}$ prior to virus assay. The pelleted (cellular) fraction was used for flow cytometry analysis (see below). 
Infectious TCRV levels were measured as $\mathrm{TCID}_{50} / \mathrm{ml}$ on Vero monolayers using an end-point dilution assay as previously described. ${ }^{12}$ Viral RNA in the CNS was measured using quantitative real-time PCR, comparing TCRV-glycoprotein (GP) transcript levels in the CNS to a standard curve as described. $^{18}$

\section{Real-time PCR and TaqMan low-density arrays (TLDA)}

Brains were collected from infected animals that were exsanguinated by transcardiac perfusion with $10 \mathrm{ml}$ ice-cold phosphate-buffered saline (PBS). The brains were then bisected along the longitudinal fissure and an entire hemisphere including the cerebrum, midbrain and cerebellum was flash frozen in liquid $\mathrm{N}_{2}$ and stored at $-80^{\circ} \mathrm{C}$. The frozen tissue was homogenized in $2 \mathrm{ml} /$ half-brain of Trizol reagent (ThermoFisher) and RNA was isolated following the manufacturers' protocol and resuspended in ultra-pure $\mathrm{ddH}_{2} \mathrm{O}$. The concentration and purity of isolated RNA were determined by spectrophotometry at 260 and $280 \mathrm{~nm}$ using a NanoDrop 1000 spectrophotometer (ThermoFisher). To eliminate potential genomic DNA contamination, the DNA-free Turbo kit (ThermoFisher) was used as per the manufacturer's protocol. Reverse transcription was performed on $1 \mu \mathrm{g}$ of total RNA, using Multiscript High Capacity Reverse Transcriptase (ThermoFisher), as per the manufacturer's protocol, using random primers. The resulting cDNA was diluted 10 -fold with ultra-pure water and stored at $-20^{\circ} \mathrm{C}$ prior to use in real-time TaqMan PCR reactions (ThermoFisher).

Mouse Immune Array TLDA cards (ThermoFisher) were used as per the manufacturers' instructions. Equal volumes of diluted cDNA and $2 \times$ Universal Taqman Master Mix were prepared. This mixture was loaded into the chambers of a Taqman Array card, which was centrifuged to distribute the cDNA throughout the card. Gene expression is expressed as fold-change relative to the indicated controls. Real-time PCR acquisition was performed using a 7900HT Fast real-time PCR machine with SDS 2.4 software or a Viia7 real-time PCR machine using Viia7 software (ThermoFisher). Automatic threshold and end points for each gene were used. Expression of selected genes was validated using individual TaqMan assays. Fold-change in gene expression was determined using the $\Delta \Delta \mathrm{Ct}$ method, ${ }^{19}$ with expression normalized to the expression of the house keeping gene glyceraldehyde 3-phosphate dehydrogenase (GAPDH) and then expressed as fold increase over the expression in age-matched uninfected controls unless indicated.

\section{Immunofluorescence immunohistochemistry (IF-IHC) and histology}

Brains were embedded in TissueTek O.C.T (Sakura-Finetek, Torrance, CA, USA) directly ex vivo in TissueTek cryo-molds (Sakura-Finetek), flash frozen in liquid $\mathrm{N}_{2}$ and stored at $-80^{\circ} \mathrm{C}$. Sections $(16 \mu \mathrm{m}$ thick) were cut as indicated using a Leica CM1900 cryostat (Leica Biosystems, Buffalo Grove, IL, USA), thaw-mounted onto SuperFrost-plus microscope slides (ThermoFisher) and then stored at $-80^{\circ} \mathrm{C}$ until staining. Prior to staining, sections were thawed and dried at room temperature (RT) for approximately $10 \mathrm{~min}$, fixed in freshly prepared 2\% paraformaldehyde in PBS for $15 \mathrm{~min}$ and permeabilized using $0.2 \%$ Tween-20 in PBS for $20 \mathrm{~min}$ at RT. Sections were blocked with $5 \%$ normal goat serum $+1 \%$ bovine serum albumin (BSA) in PBS for at least $60 \mathrm{~min}$ at RT. Primary antibodies used include rabbit anti-TCRV pAb (generated by ThermoFisher (Pierce)) by immunizing rabbits with heat-killed, sucrose gradient purified TCRV), rabbit antiglial fibrillary acidic protein (GFAP) (Dako, Carpinteria, CA, USA), rabbit anti-ionized calcium-binding adapter molecule 1 (Iba-1) (Wako Chemicals, Richmond, VA, USA); mouse antiNeuN, rabbit anti-Fox2 (EMD Millipore, Billerica, MA, USA); rat anti-CD45, rat anti-CD8 and rat anti-CD4 (BD Biosciences, San Jose, CA, USA). Tissue sections were stained overnight in a humidified chamber at $4{ }^{\circ} \mathrm{C}$ with primary antibodies diluted with $1 \%$ BSA in PBS. The slides were then rinsed with PBS and incubated with the appropriate Alexa-Fluor-conjugated (raised in goat) secondary antibodies, diluted in 1\% BSA in PBS (ThermoFisher) for $>60 \mathrm{~min}$ at RT. For detection of apoptosis, sections were prepared and stained using the ApopTag-FITC Kit (EMD Millipore) as per the manufacturer's protocol. All IF-IHC sections were mounted with ProLong Gold anti-fade mounting media containing 4'6-Diamidino-2Pheylindole (DAPI) (ThermoFisher). Fluoro-Jade B histology staining, which specifically detects neuronal degeneration, ${ }^{20}$ was performed as per the manufacturers protocol (EMD Millipore). Fluorescently labeled antibodies were detected at emission wavelengths: 405 (DAPI), 535 (Alexa-fluor 488), 605 (Alexafluor 568) or $680 \mathrm{~nm}$ (Alexa-fluor 647). Sections were imaged using a Pannoramic Digital Slide Scanner, using a $\times 20$ objective lens and appropriate filters to detect the wavelengths listed above. The images collected by the scanner were then stitched together to generate an image of the entire section. From these high-resolution scans, images were captured using Pannoramic Viewer software (3DHistech, Budapest, Hungary), and prepared with Adobe Photoshop CC 2015 software.

Quantification of terminal deoxynucleotidyl transferase dUTP nick end labeling (TUNEL) and Fluoro-Jade B+ staining was determined by selecting five regions of interest per section from two to four different mice. The individual staining channel for Fluoro-Jade and TUNEL (both green channels) was isolated and threshold was applied to isolate the positive signal. The positive signals were counted using the $3 \mathrm{D}$ Object counting module (with a size threshold of 30 pixels to eliminate nonspecific specks). This image processing and analysis were performed using the Fiji (Image J) imaging software. $^{21}$

\section{Flow cytometry}

The cellular fractions of brain homogenates (see the section Virus quantification) were pooled and resuspended in 30\% percoll (GE Life Sciences, Marlborough, MA, USA) in RPMI $+25 \mathrm{~mm}$ HEPES (ThermoFisher) and underlaid with $1 \mathrm{ml}$ of $70 \%$ percoll. After centrifugation at $800 \mathrm{~g}$ for $30 \mathrm{~min}$, CNS cells were collected from the 30-70\% interface, washed in RPMI and isolated by centrifugation at $400 \mathrm{~g}$ for $10 \mathrm{~min}$. Each 

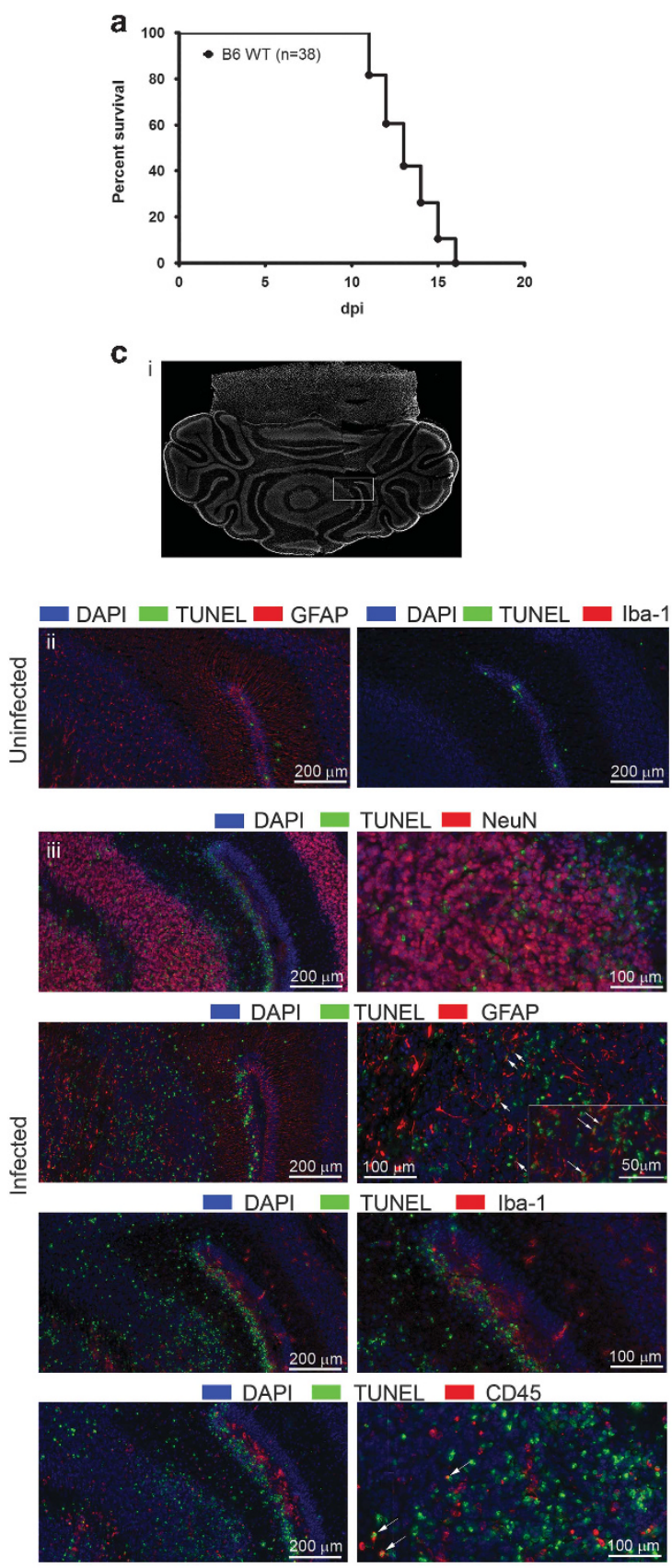

b
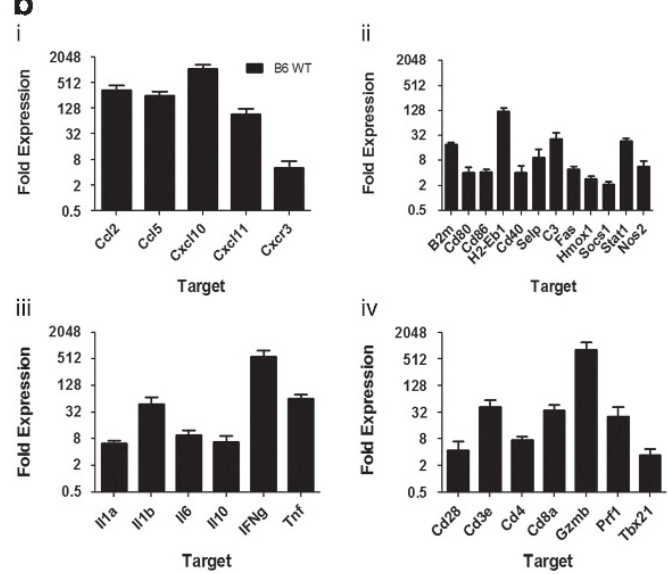

d
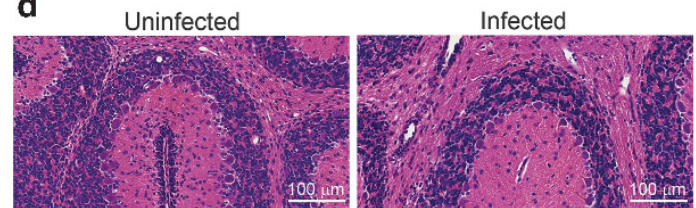

e
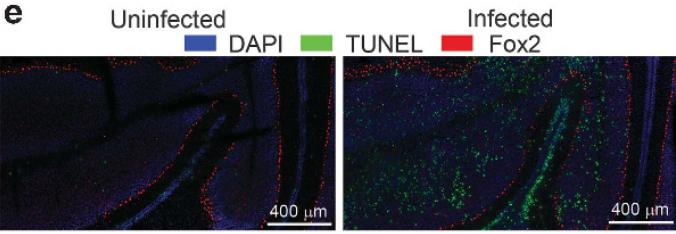

f

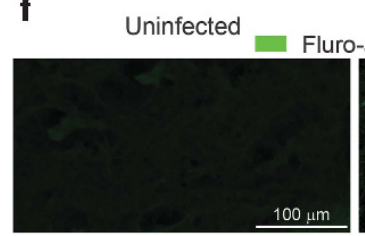

Infected
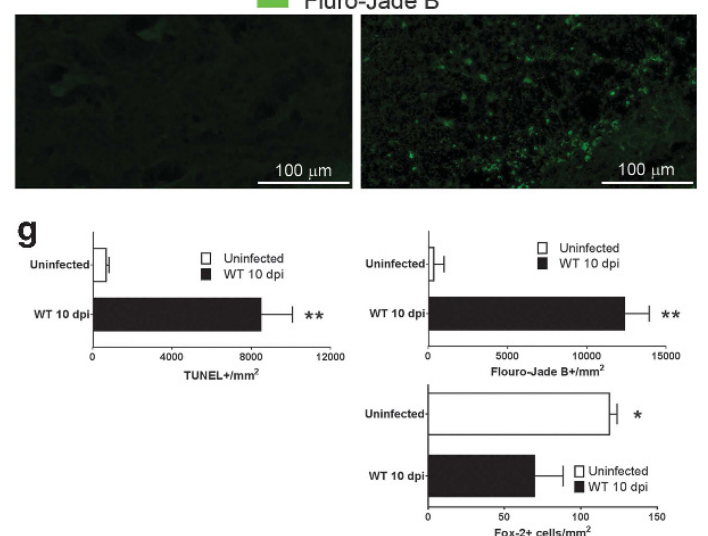

Figure 1 TCRV infection results in CNS inflammation, apoptosis and neurodegeneration. (a) Survival of C57BL/6 (B6 WT) mice infected with $2000 \times$ TCID $_{50}$ TCRV, i.p. (b) Relative quantification of gene expression in the CNS of B6 WT mice at 10 dpi: (i) chemokines, (ii) antigen presentation, (iii) cytokines and (iv) T-cell-related genes. Gene expression was normalized using GAPDH and expressed as fold change in gene expression relative to age-matched uninfected controls ( $\log _{2}$ scale; $n=6$ mice per group). (c) Apoptosis in the hindbrain of B6 WT animals at $10 \mathrm{dpi}$ (right) as detected by the TUNEL assay (coronal sections). (i) Whole section image (4'6-Diamidino-2-Pheylindole (DAPI)), with box indicating location of imaging in (ii) and (iii). (ii) Uninfected, age-matched cerebellum at P13. (iii) TCRV-infected WT mice at $10 \mathrm{dpi}$ (age=P13). TUNEL-positive cells (green) co-stained for neurons (anti-NeuN), astrocytes (anti-GFAP), microglia (anti-lba-1) or CD45+ infiltrating cells (all shown in red). Arrows in (ciii) indicate GFAP ${ }^{+} \mathrm{TUNEL}^{+}$cells or $\mathrm{CD}^{+} 5^{+} \mathrm{TUNEL}^{+}$cells, respectively. Scale bars: (ii) and left column of (iii) $=200 \mu \mathrm{m}$; right column of (iii) $=100 \mu \mathrm{m}$. Inset, GFAP+TUNEL ${ }^{+}$cells, scale bar $=50 \mu \mathrm{m}$. (d) Hematoxylin and eosin of uninfected and TCRV-infected CNS collected at $10 \mathrm{dpi}$ (sagittal sections). Scale bar $=100 \mu \mathrm{m}$. (e) TUNEL (green) and Purkinje cells $(\alpha$-Fox 2 , red) in the cerebellum (coronal sections; scale bar $=400 \mu \mathrm{m}$ ) of age-matched uninfected (left column) and TCRV-infected mice (10 dpi). (f) Fluor-Jade B stain for degenerative neurons (green). (g) Quantification of TUNEL, Fluoro-Jade B and Fox2+ cells. The mean number of cells $/ \mathrm{mm}^{2}$ counted in at least five fields of view per section from at least two mice. Statistical significance denoted as ${ }^{*} P<0.05 ;{ }^{*} P<0.01$. Abbreviations: CNS, central nervous system; TCRV, Tacaribe virus; WT, wild type; TUNEL, terminal deoxynucleotidyl transferase dUTP nick end labeling. 
experiment represents at least three independent studies performed using brains pooled from four mice.

Nonspecific antibody binding was blocked with a mix of mouse $\mathrm{F}_{\mathrm{c}}$ block (purified anti-CD16/32; BD Biosciences) and normal mouse serum for at least $15 \mathrm{~min}$. All antibodies (anti-CD45, anti-CD4, anti-CD8, anti-CD62L, anti-CD11b, antiI-E/I-A (MHC class 2), anti-CD69, anti-CD44 (BD Biosciences)) and anti-F4/80 (AbD Serotec, Raleigh, NC, USA) were directly conjugated with one of the following fluorochromes: fluorescein isothiocyanate, phycoerythrin, peridinin-chlorophyll proteins or alophycocyanin. The cells were incubated with these antibodies for $20 \mathrm{~min}$ in FACS buffer (1\% BSA in PBS), then washed with FACS buffer, fixed in $2 \%$ paraformaldehyde solution and acquired using a FACSCaliber flow cytometer (BD Biosciences). The resulting data were analyzed using FlowJo (version 10) software (FlowJo, LLC, Ashland, OR, USA). Supplementary Figure S1 shows the gates for the T-cell activation markers (CD44 and CD69) set as per isotype controls as well as the strategy for assigning CD45 low and hi cell populations to distinguish CD45hi $\mathrm{F} 4 / 80+$ infiltrating macrophages from CD45lo F4/80+ microglia.

\section{Isolation and transfer of $\mathrm{T}$ cells}

Donor T cells (total T cells, CD8+ and CD4+ T cells) were isolated from the spleens of adult WT B6 mice by negative selection using the Untouched Mouse T cell, CD8+ T cell or CD4+ T cell isolation kits, respectively (ThermoFisher) as per the manufacturer's protocols. The purity of the isolated cells was confirmed by flow cytometry to be $>90 \%$ (Supplementary Figure S2). $2.0 \times 10^{6}$ cells in serum-free RPMI were transferred by intraperitoneal injection into TCRV-infected or uninfected control recipient pups at $7 \mathrm{dpi}(\mathrm{P} 10)$ in $100 \mu \mathrm{l}$ volume using a $27 \mathrm{G}$ needle. At 15 days post-transfer (dpt), T cells isolated from uninfected animals showed successful reconstitution of the spleen and cervical lymph nodes following total T-cell transfer and infected recipient animals demonstrated similar reconstitution by flow cytometry (Supplementary Figure S3).

\section{Statistical analysis}

The significance for differences in survival was determined by the log-rank test using GraphPad Prism 5.04 (GraphPad Software, La Jolla, CA, USA). Statistical significance for individual gene expression was determined using the ANOVA or $t$-test using GraphPad Prism 7.0 (Graphpad Software) or Microsoft Excel 2010 (Microsoft Corp, Redmond, WA, USA), respectively.

\section{RESULTS}

Extensive cellular infiltration, apoptosis of astrocytes and loss of Purkinje cells in the cerebellum characterizes the lethal meningoencephalitis in TCRV-infected mice

Infection of C57BL/6 (B6 WT) neonatal mice at day 3 of life (P3) with TCRV $\left(2000 \times \mathrm{TCID}_{50}\right.$ i.p.) results in tremors, delayed righting reflex and hindlimb paralysis by 9-10 dpi, followed by death 3-5 days after (13-15 dpi; Figure 1a). As described previously, ${ }^{12}$ at $10 \mathrm{dpi}$ when the CNS viral load averages $10^{6} \mathrm{TCID}_{50} / \mathrm{ml}$, microscopic examination of the CNS shows submeningeal edema and inflammation in the cerebellum (Figure 1d). Additionally, proinflammatory gene expression occurs in the CNS (Figure 1b), as will be discussed in more detail below. TUNEL-positive apoptotic cells are present in all cell layers of the cerebellum, particularly the granular layer (Figures 1ciii and g) as compared with uninfected agematched controls, which show levels of apoptosis consistent with the developmental stage (Figure 1cii). Of note at 10-15 dpi both the viral antigen and evidence of apoptosis were mostly restricted to brain stem and cerebellum. The clinical signs and histopathology of the cerebellum suggested the apoptosis of neurons; however, IF-IHC with anti-NeuN, a nuclear marker for neurons (except Purkinje cells (PC)) in the cerebellum, shows only limited co-localization with TUNEL+ cells, indicating minimal apoptosis of neurons (Figure 1ciii and Supplementary Figure S4). Iba-1+ cells (microglia/macrophages) were found proximal to some foci of apoptosis but did not co-localize with TUNEL+ staining either. In contrast, TUNEL+ staining located between neurons within the granular layers, proximal to the PC layer (PCL) and within the matrix layer of the cerebellum co-localized with a number of GFAP+ cells as well as with CD45-infiltrating cells. Co-localization and anatomical location suggest that apoptosis is mostly occurring in GFAP+ astrocytes (Figure 1ciii and Supplementary Figure S4). This is consistent with previous studies suggesting that TCRV primarily infects astrocytes, especially protoplasmic astrocytes in the granular layers. ${ }^{12}$

Purkinje cells are required for balance and infected mice showed irregular gait, delayed righting reflex and reduced balance. Interestingly, although hematoxylin and eosin staining of the CNS indicated a disruption of the Purkinje cell layer of TCRV-infected animals by $10 \mathrm{dpi}$ (Figure 1d), Fox $2+\mathrm{PC}^{22} \mathrm{did}$ not stain TUNEL+ (Figure 1e). However, Fluoro-Jade B staining indicated widespread neuronal degeneration (Figures $1 \mathrm{f}$ and $\mathrm{g})^{20}$ and a significant reduction in the number of Fox $2+$ cells in the PCL of TCRV-infected animals was observed (Figure 1g, $P<0.05)$. Together, these data show that TCRV infection and the inflammatory response it induces result in neuronal degeneration and loss of PC in the cerebellum secondary to apoptosis of neuron-supporting astrocytes in the cerebellum.

\section{T cells and macrophages infiltrate the CNS parenchyma in response to TCRV infection of the CNS}

Previous studies had established that TCRV is a non-cytolytic virus and that disease required the presence of $\mathrm{T}$ cells as mice thymectomized early in life as well as RAG KO mice showed no clinical evidence of encephalitis. ${ }^{14}$ To explore directly the role of the immune response in disease we first assessed whether the immune cells infiltrated the CNS of TCRV-infected mice. Flow cytometry of single-cell suspension from the CNS at $10 \mathrm{dpi}$ showed that 20\% of microglia (CD45lo; Figure 2ai) in the CNS have increased expression of MHC class 2 ((H2-Eb1, Class 2; Figure 2ai), compared with $<1 \%$ in age-matched uninfected controls. This is consistent with the activation of microglia and the increased levels of interferon gamma (IFN $\gamma) \cdot{ }^{15,23}$ In 
a

i
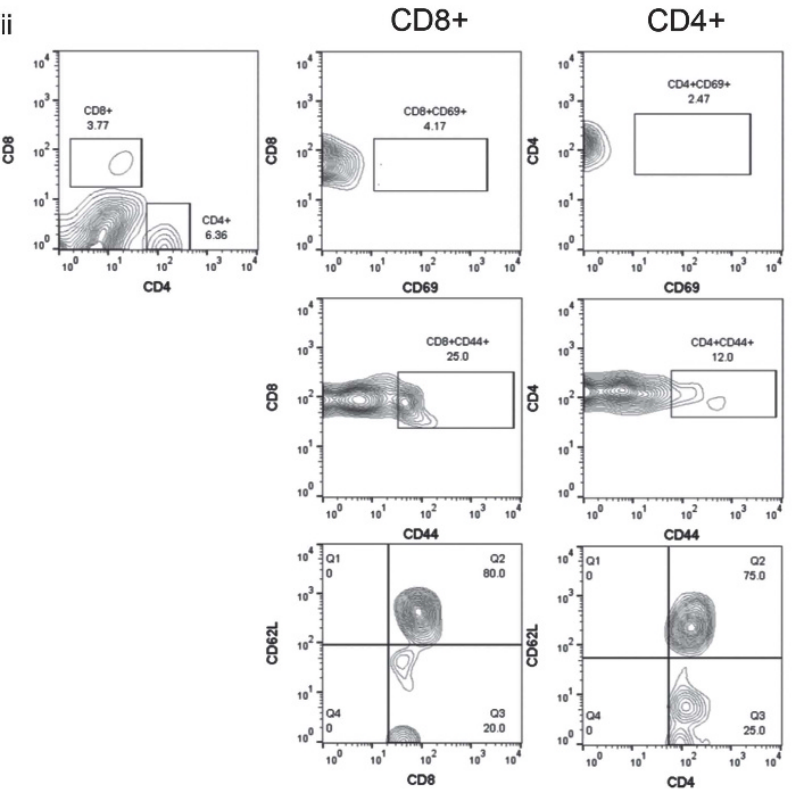

Uninfected

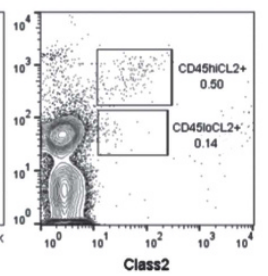

CD4+

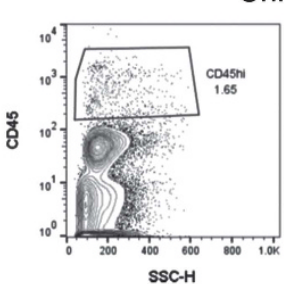

CD8+
Uninfected

b

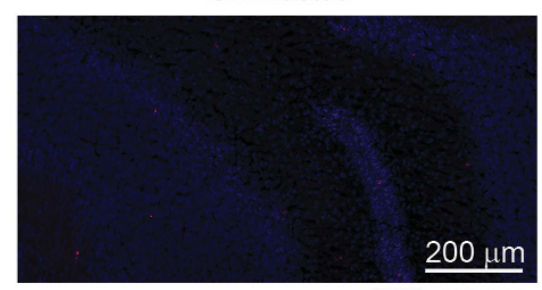

DAPI

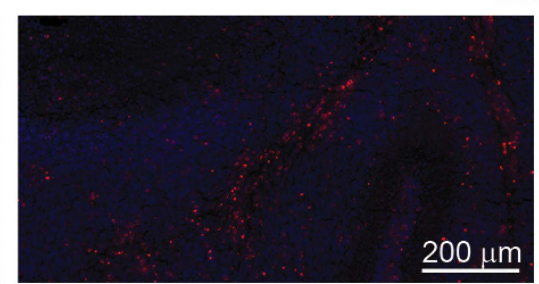

CD45

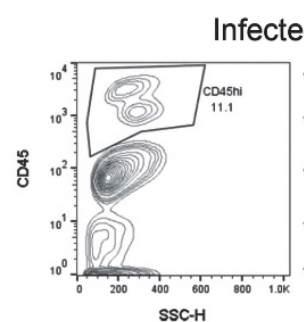

Infected, 10 dpi

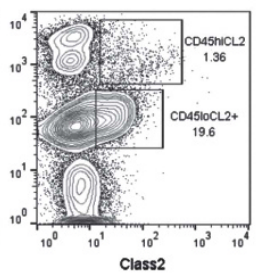

CD8+
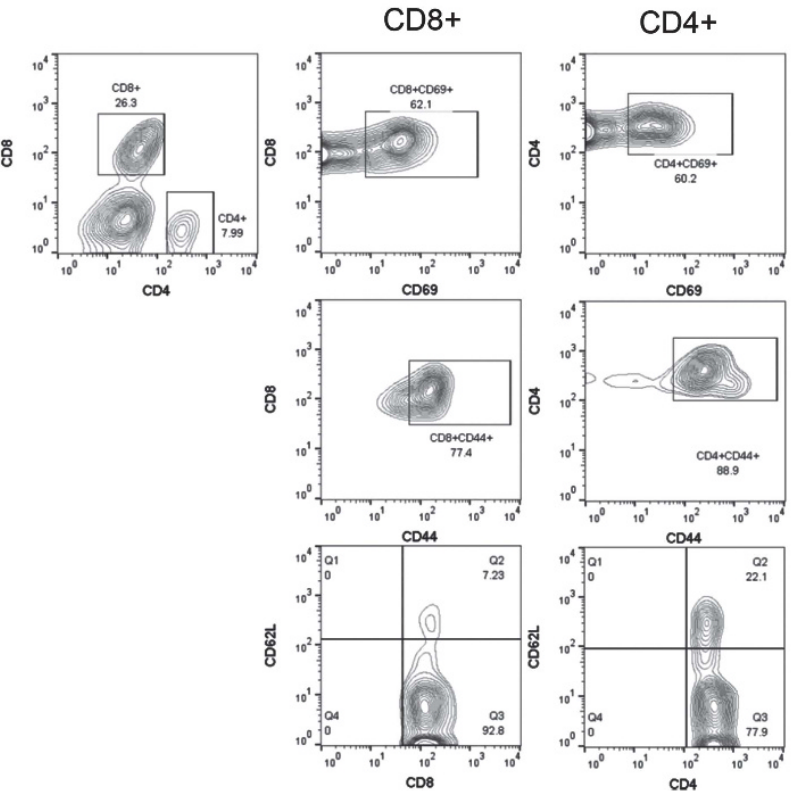

Infected

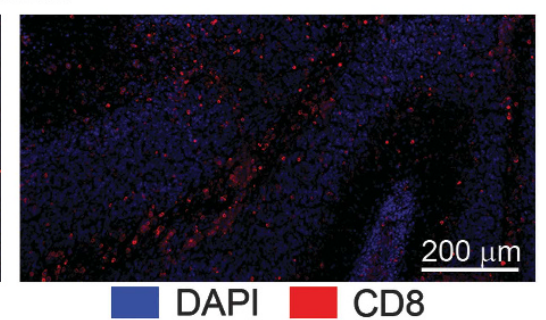

Figure 2 Characterization of cellular infiltration and microglial activation in CNS of infected mice and the activation of microglia. (a) CNS cells isolated from age-matched TCRV-infected and uninfected controls (left) mice at $10 \mathrm{dpi}$ (right) were analyzed by flow cytometry. Populations are described as percentages of the parent population (SSC-H, side scatter). The gating strategy shown in Supplementary Figure S1. Data are representative of at least three independent experiments, and $>4$ mice were pooled for each experiment. (b) IF-IHC of immune cells in the cerebellum (coronal sections, same anatomical location as Figure 1c) at 10 dpi. Images are representative of six mice from two independent experiments). Scale bar $=200 \mu \mathrm{m}$. Abbreviations: CNS, central nervous system; IF-IHC, immunofluorescence immunohistochemistry; TCRV, Tacaribe virus.

addition, infected mice showed an increase in infiltrating peripheral immune cells (CD45hi, 20\% of live cells), consisting primarily of CD45hi, CD11b ${ }^{+}, \mathrm{F} 4 / 80^{+}$macrophages ( $30 \%$ of CD45hi cells; Supplementary Figure S1) and CD8+ T cells ( $25 \%$ of the CD45hi cells; Figure 2aii). Most infiltrating T cells were CD62L - CD44+ (90\% CD8+ and 75\% CD4+; Figure 2aii), whereas greater than $50 \%$ of the infiltrating $\mathrm{T}$ cells were positive for CXCR3, a receptor for CXCL10/11, and known to drive T-cell responses into the CNS (data not shown and see refs 24,25). IF-IHC of coronal sections of the cerebellum show at $10 \mathrm{dpi}$ that CD45+-infiltrating cells are not periventricular (data not shown) or meningeal as reported in the acute LCMV encephalitis model, ${ }^{25}$ but instead fully penetrate all layers of the cerebellum of TCRV-infected animals (Figure 2b).

To gain a better understanding of the response elicited by the virus we examined changes in gene expression in the CNS at the onset of clinical disease (10 dpi) using semiquantitative real-time PCR. The CNS of TCRV-infected mice at day $10 \mathrm{dpi}$ had increased expression of proinflammatory cytokines and chemokines (Figure 1b), including IFN $\beta$, IL-6, IL-1 $\beta$, TNF, CXCL10, CXCL11, CCL5 and CCL2, as well as complement 
component $C 3$ relative to age-matched uninfected controls. The increased expression of $\beta 2$ microglobulin $(\beta 2 \mathrm{~m})$, MHC class 2 (H2-Eb1) and co-stimulatory molecules CD80, CD86 and $C D 40 L$ (Figure 1bii), combined with an increase in nitric oxide synthase 2 (NOS2) expression and heme oxygenase 1 (Hmox1), suggest there is activation of microglia and/or infiltrating macrophages, which could include M1 (increased Nos2, STAT1) and M2 (increased Hmoxl) phenotypes. ${ }^{26}$ Lastly, there are significant increases in the expression of T-cell-related genes, including $C D 3, C D 4$ and $C D 8$, effector molecules: granzyme B $(\mathrm{Gzmb})$, and perforin 1 (Prf1), as well as cytokines $I F N \gamma$ and $I L-10$ (Figure $1 \mathrm{bi}$ ), corresponding with the observed infiltration of $\mathrm{T}$ cells into the CNS in response to TCRV infection. Notably, there is no increase in $I L-17$ or FoxP3 expression, suggesting that neither regulatory $\mathrm{T}$ cells nor $\mathrm{T}_{\mathrm{H}} 17$ $\mathrm{T}$ cells infiltrate the CNS in this model.

\section{Role of $T$ cells in TCRV immune-mediated pathology}

To confirm the role of T cells in the disease, we utilized CD3e $\mathrm{KO}$ mice, which lack functional $\mathrm{T}$ cells and, as previously reported, survive TCRV infection ${ }^{12}$ despite harboring viral loads similar to those of WT mice (Figure 3ai). Ten days post infection $\mathrm{CD} 3 \varepsilon \mathrm{KO}$ mice showed significantly lower expression of genes linked to CNS inflammation, as compared with infected WT controls (Figure 3aii). Of note, even in the absence of $\mathrm{T}$ cells the virus induces low levels of mRNA expression for CCL2, CCL5 and CXCL10, likely secondary to virus-induced type 1 IFN (Figure 3biii), as well as TNF and C3 at $10 \mathrm{dpi}$. This modest inflammatory response in the CNS does not result in clinical disease or death (Figure $3 \mathrm{bi}$ ).

To confirm the pathogenic role of T cells, infected CD3e KO pups received total $\mathrm{T}$ cells isolated by negative selection on P10 (7 dpi), harvested from: (1) the spleens of uninfected B6 mice, (2) B6 mice that survive TCRV challenge at P7 (convalescent $\mathrm{T}$ cells) or (3) OT-1 transgenic (tg) mice. As shown in Figure 3bi, all mice developed similar levels of viral RNA in the CNS; however, only mice receiving naïve or convalescent WT total T cells replicated the disease of WT mice. Mice that received naïve $\mathrm{WT}$ total $\mathrm{T}$ cells demonstrated reduced activity, tremors and hindlimb paralysis 13-15 dpt, followed by death 3-6 days later, similar to WT animals (Figure 3bi). By comparison, mice that received $\mathrm{T}$ cells derived from TCRVinfected convalescent mice displayed accelerated pathology developing paralysis $6-8 \mathrm{dpt}$ and dying by $7-10 \mathrm{dpt}$. In contrast, $\mathrm{CD} 3 \varepsilon \mathrm{KO}$ mice that received $\mathrm{T}$ cells isolated from OT-1 transgenic mice did not develop disease, despite similar levels of viral nucleoprotein (NP) RNA in the CNS (Figure 3bi), indicating that a virus-specific T-cell response is required for pathogenesis. As expected, $\mathrm{CD} 3 \varepsilon \mathrm{KO}$ mice that were infected on $\mathrm{P} 3$ but did not receive $\mathrm{T}$ cells survived the infection. However, when those that received T cells at $30 \mathrm{dpi}$, $50 \%$ of the animals succumbed to encephalitis within $30 \mathrm{dpt}$, indicating that the $\mathrm{T}$ cells can induce CNS damage in persistently infected mice (Figure 3bi). As expected, neither $\mathrm{CD} 3 \varepsilon \mathrm{KO}$ mice receiving vehicle only nor uninfected mice receiving WT T cells developed symptoms (Figure 3bi and data not shown).

To characterize further the effect of the T cells, recipients of naïve $\mathrm{T}$ cells were killed at $15 \mathrm{dpt}$, when mice had developed significant neurological symptoms (loss of balance, righting reflex, tremors) or paralysis. Flow cytometry showed that $20-30 \%$ of the live cells isolated from CNS of these mice were CD45hi-infiltrating cells, of which approximately $70 \%$ were $\mathrm{T}$ cells $(45-50 \% \mathrm{CD} 8+\mathrm{T}$ cells and $25-30 \% \mathrm{CD} 4+\mathrm{T}$ cells; Figure $3 \mathrm{c}$ ). As in WT mice, the CD4+ and $\mathrm{CD} 8+\mathrm{T}$ cells infiltrated the parenchyma and had an activated phenotype (>90\% CD44+, CD62L-; Figure 3c). Aged-matched, uninfected controls receiving naïve $\mathrm{T}$ cells showed only trace CD45hi infiltrates by flow cytometry, consisting primarily of $\mathrm{T}$ cells and only very rare CD45+ cells were observed in the parenchyma by IF-IHC (Figure 3civ).

Assessment of gene expression in the CNS of these mice at $15 \mathrm{dpt}$ showed that infected $\mathrm{CD} 3 \varepsilon \mathrm{KO}$ mice receiving naïve total $\mathrm{T}$ cells displayed increased mRNA expression for genes linked with T-cell infiltration $(C D 3, C D 4, C D 8, G z m B, \operatorname{Prf1})$, inflammation (TNF, IL-1 $\beta, I F N \gamma$ ) and antigen presentation ( $\beta 2 m, H 2-E b 1, C D 80$ and CD86). This pattern of expression was very similar to infected WT mice at 10 dpi (compare Figures 3aii and bii, red lines). T-cell recipient mice showed higher levels of CCL2, CCL5, CXCL10 and CXCL11 as well as NOS2, C3 and CCR2 RNA expression, indicating the activation of microglia and/or the infiltration of macrophages into the CNS, comparable to that of infected WT mice. (Figure 3bii). In contrast, those that received $\mathrm{T}$ cells isolated from OT-1 transgenic mice did not show increased expression of inflammatory genes (Figure 3bii, green line).

Lastly, histopathological examination of CNS sections at 15 dpt by IF-IHC showed similar results to those observed in infected WT mice, including TUNEL-positive cells in the granular layers, particularly GFAP+ astrocytes (Figure 4b, arrows last column), while TUNEL+, NeuN+ nuclei (Figure $4 \mathrm{~b}$ ) were absent. Further, we observed engorgement of the microglia, as indicated by increased Iba-1 and GFAP-positive cells as well as a loss of Fox2+ cells, indicating a loss of PC (Figure 4c) in the cerebellum and an increase in Fluoro-Jade B-positive cells (Figure 4d). Age-matched controls, both untransferred, TCRV-infected (Figure $4 \mathrm{~b}$ ) and uninfected $\mathrm{CD} 3 \varepsilon \mathrm{KO}$ mice that received $\mathrm{B} 6 \mathrm{WT} \mathrm{T}$ cells, presented no significant cellular infiltration or apoptosis in the CNS (Figure 4), a near absence of apoptotic cells, minimal or no gliosis and no indication of neuronal pathology (Figure 4b).

The results above confirmed that $\mathrm{T}$ cells penetrate the parenchyma and play a key role in initiating and amplifying the pathogenic immune response against TCRV infection. Thus, we reasoned that the maturation of the blood brain barrier (BBB) could contribute to the exclusion of lymphocytes and the increased resistance to TCRV meningoencephalitis observed in older mice. To explore this, neonatal $\mathrm{CD} 3 \varepsilon \mathrm{KO}$ mice were infected with TCRV at P3 and left untreated. Transfer of naïve total $\mathrm{T}$ cells $\left(2.0 \times 10^{6}\right.$ cells, intravenously) into persistently infected $\mathrm{CD} 3 \varepsilon \mathrm{KO}$ mice at $5-6$ weeks of age 


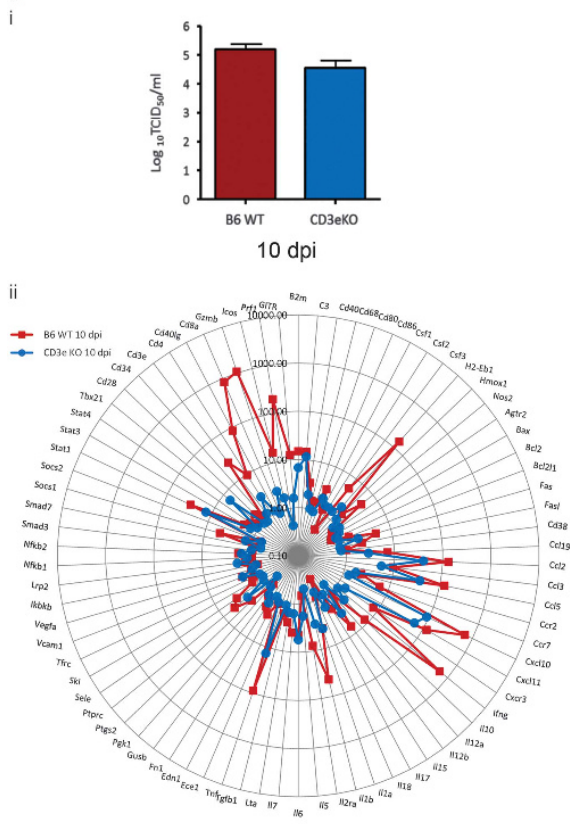

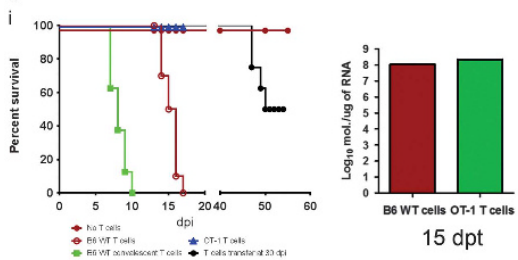

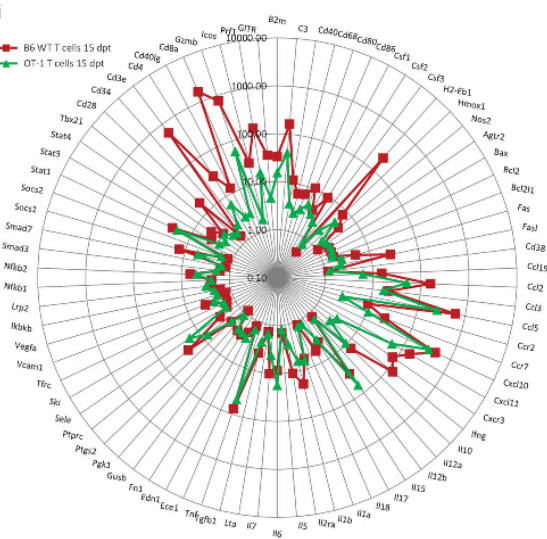

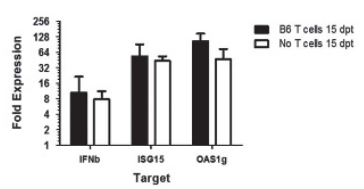

c

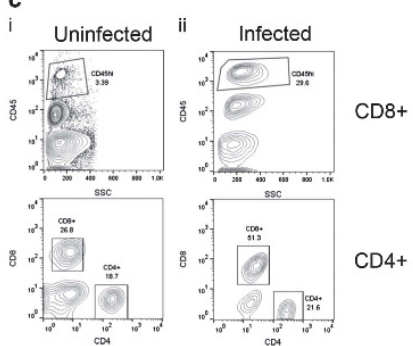

iii
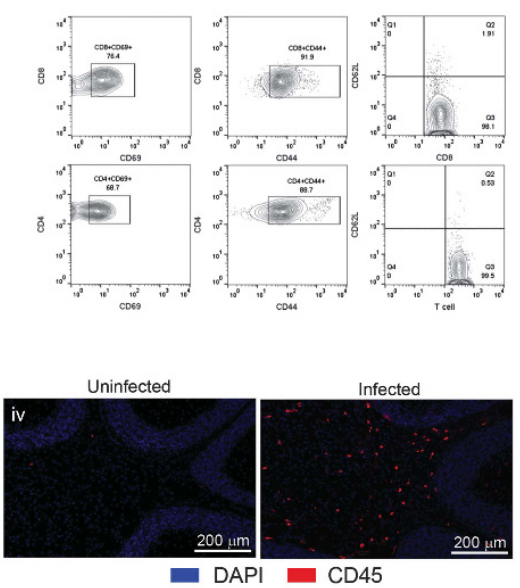

Figure 3 T cells infiltrate the TCRV-infected CNS and drive inflammation and disease. (a) TCRV induced encephalitis in T-cell-deficient mice. (i) Viral loads in CNS of infected WT or CD3ع KO mice at 10 dpi as determined by $T_{C I D}$ assay. (ii) Changes in gene expression in CNS of TCRV-infected B6 WT (red) or CD3 $\varepsilon$ KO mice (blue) relative to uninfected age/strain-matched controls as determined by TLDA at day $10 \mathrm{dpi}$ ( $n=4$ /group). (b) Transfer of T cells restored pathology in CD3 $\varepsilon$ KO mice. (i) Left: Survival curve of mice infected on P3 and receiving $2 \times 10^{6}$ T cells at $7 \mathrm{dpi}$ from naïve B6 WT mice (WT T cells), B6 WT mice pre-exposed to TCRV (B6 WT convalescent T cells), naïve OT-1 tg mice (OT-1 T cells). Alternatively CD3 $\varepsilon$ KO mice were transferred with naïve T cells 30 dpi (T-cell transfer at 30 dpi). Controls (no T cells) include infected mice that did not receive a T-cell transfer ( $N=>8$ mice per group). Right: Viral loads in infected $\mathrm{CD} 3 \varepsilon \mathrm{KO}$ mice that received OT-1 tg T cells (green) or B6 WT T cells (red) at 7 dpi as determined by quantitative real-time PCR of TCRVGP ( $N=6$ /group). (ii) Relative changes in gene expression at $15 \mathrm{dpt}$ in infected mice that received B6 WT and OT-1 tg T cell relative to age-matched, uninfected, untreated $\mathrm{CD} 3 \varepsilon \mathrm{KO}$ mice ( $n=3$ /group) and normalized to the expression of GAPDH. (iii) Changes in mRNA expression for IFN- $\beta$ and representative interferon-stimulated genes in the CNS of TCRV-infected CD3 $\varepsilon$ KO mice that received T cells from naïve B6 WT mice (B6 T cells $15 \mathrm{dpi}$ ) compared with TCRV-infected CD3ع KO mice that did not receive T cells. Values expressed as fold changes over those of uninfected $\mathrm{CD} 3 \varepsilon \mathrm{KO}$ controls ( $N=6$ per group). (c) Flow cytometry on cells isolated from the CNS of CD3 $\varepsilon$ KO that received T-cell transfers at $15 \mathrm{dpt}$ (representative of three independent experiments, each with cells pooled from $>4$ mice). (i) Agematched uninfected control mice receiving naïve T cells. (ii) Cells isolated from CNS of TCRV-infected, CD3ع KO T-cell recipient mice. (iii) Gated on CD45hi populations (ii), phenotyping of CD8+ (top row) and CD4+ (bottom row) for expression of CD69, CD44 and CD62L, respectively. (iv) IF-IHC of infiltrating cells (CD45+, red) in the cerebellum (sagittal sections) of uninfected (top) or infected (bottom) naïve B6 WT T-cell recipients at $15 \mathrm{dpt}$. Abbreviations: CNS, central nervous system; IF-IHC, immunofluorescence immunohistochemistry; IFN- $\beta$, interferon beta; TCRV, Tacaribe virus; TLDA, TaqMan low-density arrays; WT, wild type.

resulted in encephalitis and death $(50 \%)$ by $30 \mathrm{dpt}$. These results indicate that while the susceptibility to virus infection is limited to neonates (prior to P5), the T-cell driven fatal encephalitis observed following neonatal TCRV infection is independent of age.

Together these data show that TCRV infection elicits a modest inflammatory response characterized by the upregulation of type I IFN, chemokine and proinflammatory cytokine gene expression that is insufficient to induce disease in the CNS. The infiltration of $\mathrm{T}$ cells into the parenchyma of the CNS following infection drives inflammation in the CNS, gliosis and apoptosis of non-neuronal cells, neuronal degeneration, and loss in the granular and PCLs, but no reduction in viral load.

\section{Differential pathology induced by CD8+ and CD4+ T-cell subtypes in the CNS}

The roles of CD4+ and CD8+ T cells in CNS viral infections vary from pathogen to pathogen. As shown above, both the B6 WT and T-cell recipient models showed a marked preponderance of CD8+ T cells infiltrating the CNS even when there are similar or higher levels of CD4+ $\mathrm{T}$ cells in the periphery (Supplementary Figure S3 and unpublished observation). Therefore, we next explored whether CD4+ $\mathrm{T}$ cells are 


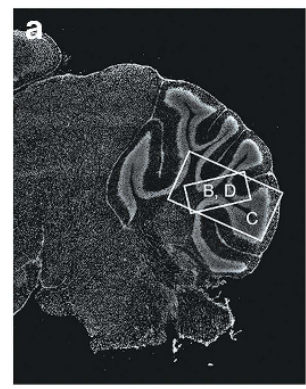

T cells
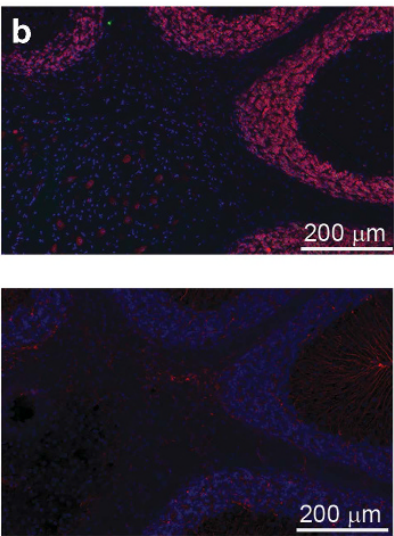

$200 \mu \mathrm{m}$

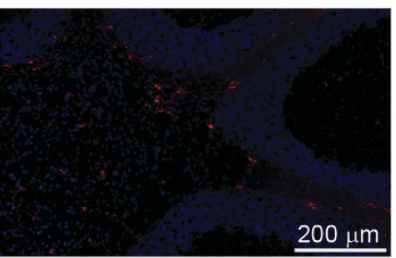

T cells

$\square$

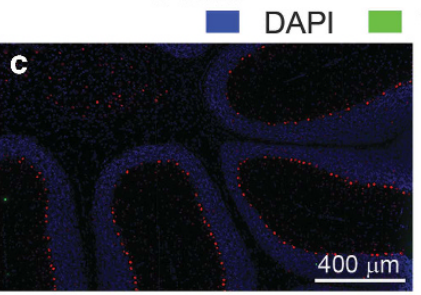

\section{TUNEL}

$$
\text { TC }
$$

TCRV

DAPI

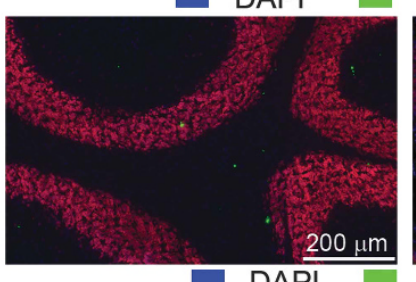

DAP
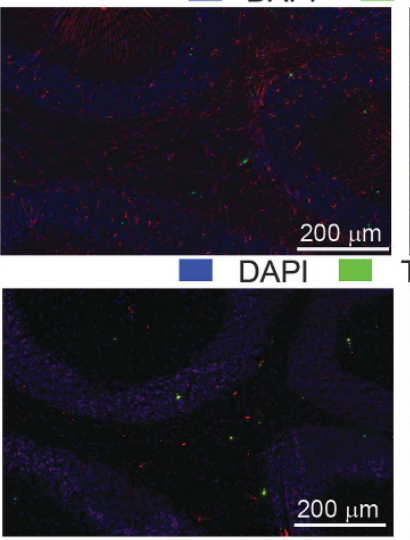

TUNEL
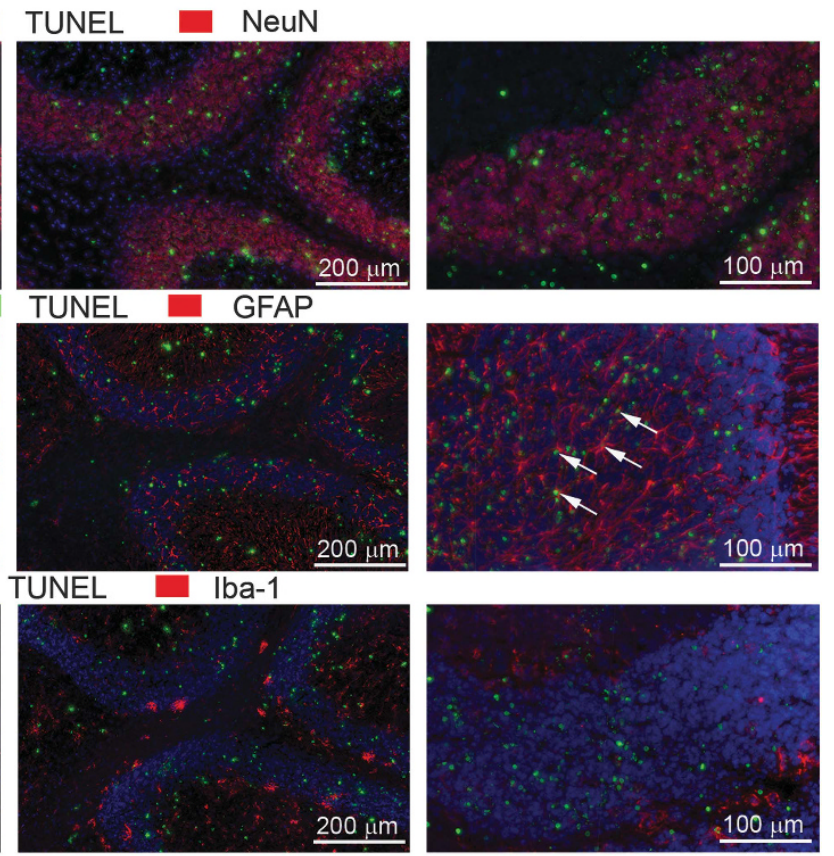

e

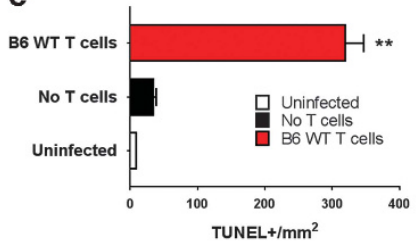

Fluoro-Jade B
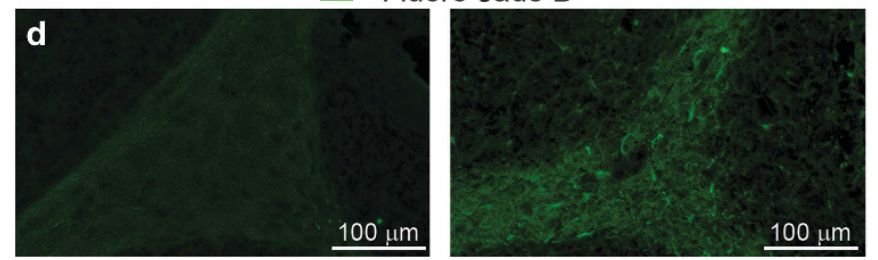
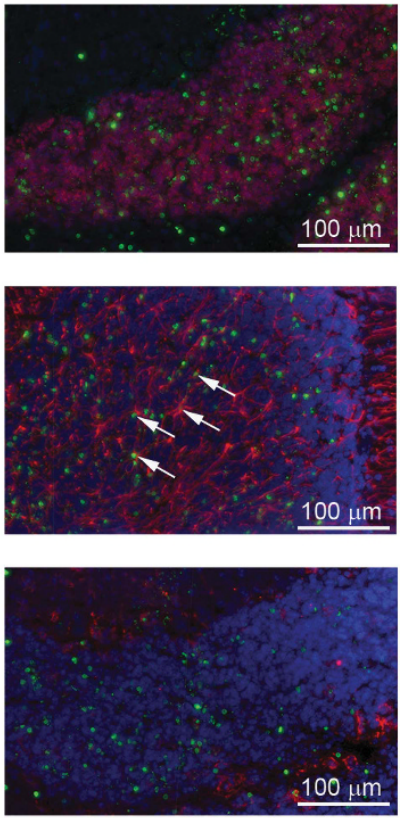

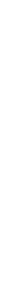


necessary for pathology by transferring purified CD8+ T cells into P10, TCRV-infected CD3e KO mice (7 dpi). These mice developed ataxia, tremors and paralysis, succumbing to disease by $15-18 \mathrm{dpt}$ (Figure 5a) reconstituting the clinical disease observed in T-cell sufficient mice. The clinical disease was associated with increased expression of genes linked to the T-cell infiltration (CD3, CD8, CXCR3) and T-cell effector molecules (GzmB, Prf1, IFNg, IL-10), as well as genes associated a
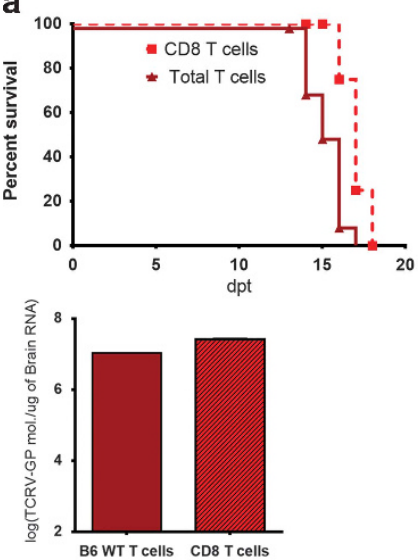

d
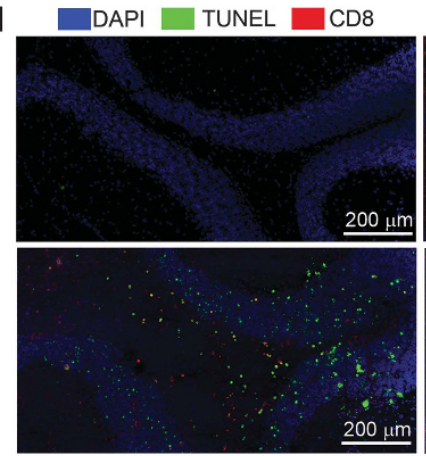

$\mu \mathrm{m}$

e
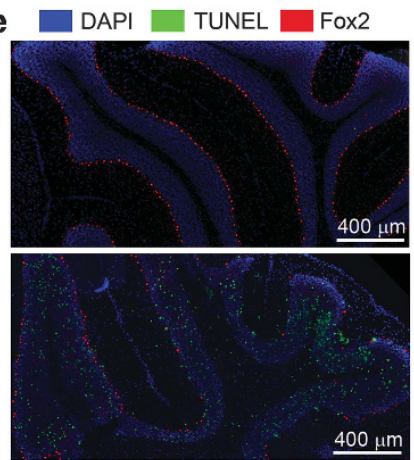
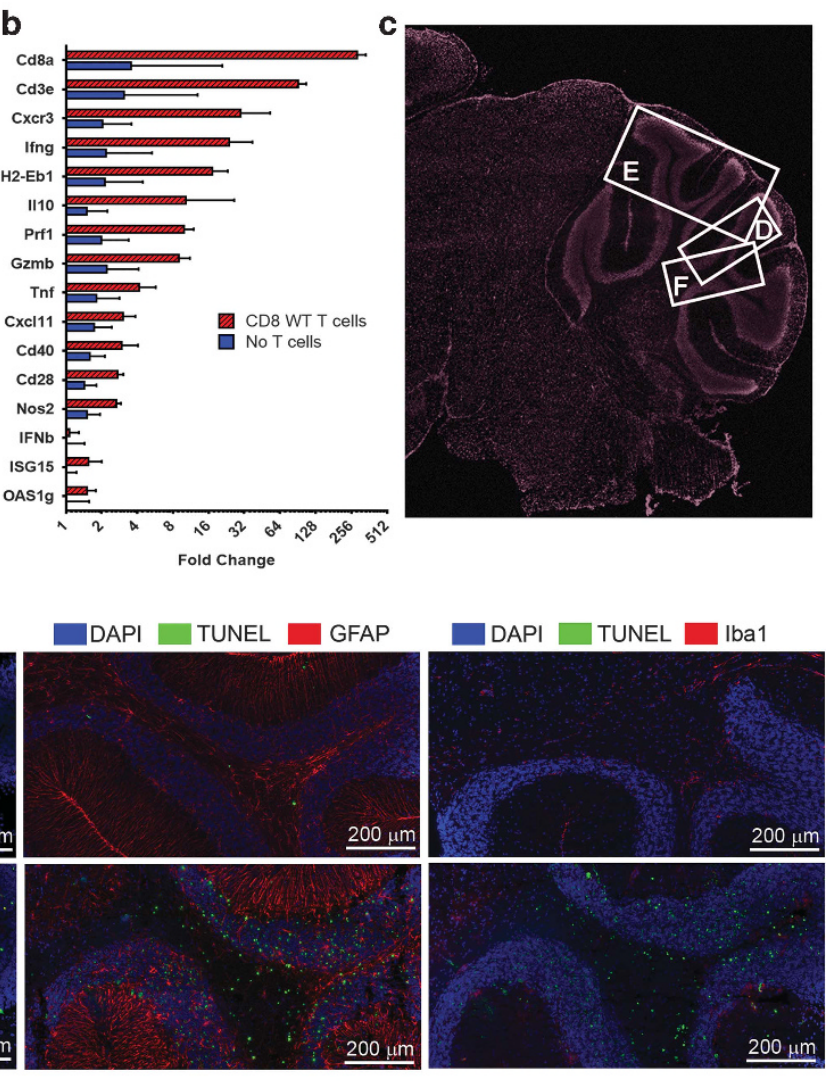

g

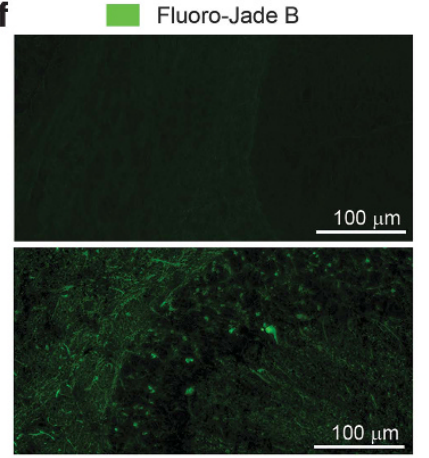

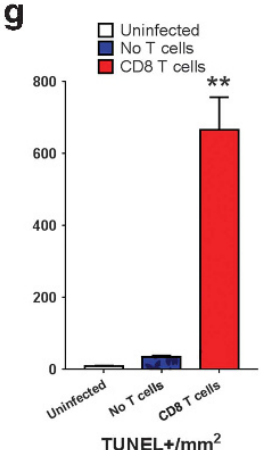

Figure 5 CD8 T cells are associated with apoptosis and acute neuronal disruption. (a) Survival curve (left) and viral load (right) of CD3 $\varepsilon$ $\mathrm{KO}$ mice that received purified CD8+ T cells (circle) or total T cells (squares) from naïve B6 WT mice. Absolute quantification of TCRV-GP transcripts in the CNS of infected B6 WT total and CD8+ T-cell recipients was determined at $15 \mathrm{dpt}$. (b) Relative gene expression in the CNS of TCRV-infected CD3 $\varepsilon$ KO mice receiving CD8+ T cells. Data are expressed as mean fold-change over the average of age-matched, TCRV-infected untransferred CD3KO controls ( $n=6$ per group) and normalized to the house keeping gene, GAPDH. Error bars $=\mathrm{s} . e . \mathrm{m}$. (c) Whole-cerebellum image (sagittal sections, 4'6-Diamidino-2-Pheylindole (DAPI)), with boxes indicating location of imaging for d-f). (d-f) Sections from uninfected CD3 $\varepsilon$ KO receiving CD8+ T cells at P10 (left) and TCRV-infected CD3 $\varepsilon$ KO receiving CD8+ T cells at 15 dpt, stained for: (d) TUNEL+ cells (green), combined with anti-CD8 (T cells); astrocyte (anti-GFAP) or microglia (anti-lba-1) staining (red). Scale bar $=200 \mu \mathrm{m}$. (e) TUNEL+ cells (green), combined with Purkinje cells (anti-Fox2). Scale bar $=400 \mu \mathrm{m}$. (f) Fluoro-Jade B stain for degenerative neurons (green). Scale bar $=100 \mu \mathrm{m}$. Images are representative of $N=4$ animals, in two independent experiments. (g) Quantification of TUNEL+ cells. The mean number of cells $/ \mathrm{mm}^{2}$ counted in at least five fields of view per section from at least two mice. Statistical significance denoted as ${ }^{* *} P<0.01$. Abbreviations: CNS, central nervous system; TCRV, Tacaribe virus; TUNEL, terminal deoxynucleotidyl transferase dUTP nick end labeling; WT, wild type. 
with microglia activation (antigen presentation genes, $\mathrm{H} 2-\mathrm{E} b 1$, Nos2, TNF) at $15 \mathrm{dpt}$ (Figure 5b), as compared with infected $\mathrm{CD} 3 \varepsilon \mathrm{KO}$ mice that did not receive $\mathrm{T}$ cells. Accordingly, microscopic examination of the CNS at $15 \mathrm{dpt}$ showed infiltrating CD8+ T cells at all depths of the CNS parenchyma, and GFAP+ TUNEL+ cells, likely astrocytes, throughout the cerebellum, particularly in the granular layer as observed in infected WT mice (Figures 5d and g). These mice also showed marked PC loss at the PCL of the cerebellum (Figure 5e) as well as increased Fluoro-Jade B staining in all cellular layers of the cerebellum (Figure 5f). Moderate engorgement of the microglia was evident as indicated with Iba-1 staining (mostly localized to the white matter and matrix layers, proximal to the granular layers).

Previous studies in other neural tropic viruses had shown that $\mathrm{CD} 4+\mathrm{T}$ cells contribute to antiviral responses by producing cytokines and chemokines that enhance CD8+ T-cell function as well as through direct cytotoxic effects. ${ }^{28}$ Since CD4+ $\mathrm{T}$ cells infiltrate the CNS (Figures 2 and 3), we next determined whether they played a direct role in the disease. As shown in Figure 6, transfer of purified $\mathrm{CD} 4+\mathrm{T}$ cells into infected $\mathrm{CD} 3 \varepsilon \mathrm{KO}$ mice resulted in a different clinical outcome. These mice did not show signs of encephalitis until 20-25 dpt, when they became lethargic and unresponsive to stimuli with the majority (80\%) ultimately succumbing to disease by $30 \mathrm{dpt}$ (Figure 6a). Interestingly, before developing signs of encephalitis, at $15 \mathrm{dpt}$, mice that received $\mathrm{CD} 4+\mathrm{T}$ cells showed upregulation of GzmB, Prfl and IFN- $\gamma$ (relative to infected $\mathrm{CD} 3 \varepsilon \mathrm{KO}$ mice which had not received $\mathrm{T}$ cells) similar to that observed in mice transferred with CD8+ T cells (Figure $6 \mathrm{~b}$ ). However, these mice also showed greater expression for genes linked to macrophage/microglia activation, including costimulatory (CD40, CD86, H2-Eb1, Hmox1) and inflammation (C3, TNF, Nos2, IL-1a, IL-1b) molecules (Figure 6b), when compared with CD8+ T-cell recipients (Figure 5b).

IF-IHC at $15 \mathrm{dpt}$ confirmed the presence of CD4+ T cells in the parenchyma of the CNS (Figure 6d). Indeed, these mice showed no evidence of increase in apoptotic (TUNEL-positive) cells (Figures $6 \mathrm{~d}$ and g), neuronal degeneration (Figure 6f) or loss of PC (Figure 6e). Instead, CD4+ T-cell recipients showed an anatomically diffuse increase in Iba- 1 bright, activated microglia/macrophage staining throughout the cerebellum, with a moderate increase in GFAP staining, indicating widespread activated microglia (Figure 6d) instead of the localized gliosis observed in CD8+ T-cell recipients and WT animals.

Lastly, as mice that received CD4+ $\mathrm{T}$ cells do not succumb until 20-30 dpt, we next examined whether the absence of neuronal degeneration and apoptosis in CD4+ T-cell recipients was due to slower disease kinetics or reflected a difference in pathobiology. IF-IHC at $28 \mathrm{dpt}$, when the animals became lethargic and hunched, did not show an increase in TUNELpositive cells or significant loss of PC or neurodegeneration in the cerebellum despite persistently TCRV-infected cells (Figure 7). Surprisingly, by this time we did not observe an increase in cerebellum microgliosis despite the continued presence of some $\mathrm{CD} 4+\mathrm{T}$ cells and virally infected cells.
Instead, by day 28 the viral antigen was detected with a polyclonal anti-TCRV antibody in more rostral regions of the CNS, particularly the cerebral cortex and hippocampus, and was associated with extensive gliosis (increased Iba-1 and GFAP staining) (Figure 7). Small numbers of CD4+ $\mathrm{T}$ cells were evident in these regions. Lastly, by $28 \mathrm{dpt}$, there was no increase in TUNEL+ cells but foci of degenerative neurons were evident in the cortex and hippocampus by Fluoro-Jade B staining.

Combined, these data suggest that CD8+ T cells, which are the predominant T-cell population in the CNS responding to TCRV infection, mediate apoptosis of astrocytes and rapid neuronal cell loss, even in the absence of CD4+ T-cell help, and are largely responsible for the acute death observed in T-cell replete mice. In contrast, mice that only receive $\mathrm{CD} 4+\mathrm{T}$ cells survive longer, but the persistent TCRV infection eventually spreads rostrally, leading to widespread inflammation and gliosis. This inflammation was associated with non-apoptotic neuronal degeneration in several regions of the CNS, particularly the cerebral cortex and hippocampus. As such, acute and subacute TCRV encephalitis may require distinct therapeutic approaches to reduce tissue damage and prevent mortality.

\section{DISCUSSION}

For decades, the CNS was considered an immunologically privileged site that kept lymphoid cells beyond the blood brain barrier and was devoid of lymphatics. We now know that glial cells (astrocytes and microglia) armed with a full complement of innate immune receptors constantly surveil the CNS environment, acting as innate immune sentinels of injury or infection and are capable of antigen presentation. Further, lymphatic structures embedded in the dura mater sinuses drain antigen from the CNS into the deep cervical lymph nodes and provide a path for peripheral immune cells to sense and respond to CNS antigens. ${ }^{29}$ Lastly, lymphocytes penetrate the $\mathrm{BBB}$ in response to cytokine and chemokine production in the CNS following infection and are critical for viral clearance. ${ }^{30-32}$ These factors suggest that adoptive immunotherapies or cytoimmunotherapies could be effective in combating entrenched viral infections of the CNS. ${ }^{16,33,34}$ While this approach has proven successful in neonatal models of LCMV Armstrong infections, the consequences in other CNS viral infections are not fully understood. Preventing damage to irreplaceable terminally differentiated neurons during infections, infarcts and other injuries of the CNS requires a precise balance between proinflammatory and anti-inflammatory mechanisms. ${ }^{35}$ Thus understanding the role immune cells play in the balance between effective viral clearance and neurological damage is critical to the development of these therapies.

Our studies show that early on arenavirus TCRV infects predominantly astrocytes in the cerebellum and brain stem, suggesting that this causes secondary neurodegeneration and loss of cerebellar neurons, most notably Purkinje cells. As is the case with other arenavirus infections, such as the well-studied LCMV model, our studies confirm that this pathology is not mediated directly by the virus, which is non-cytolytic, and in 

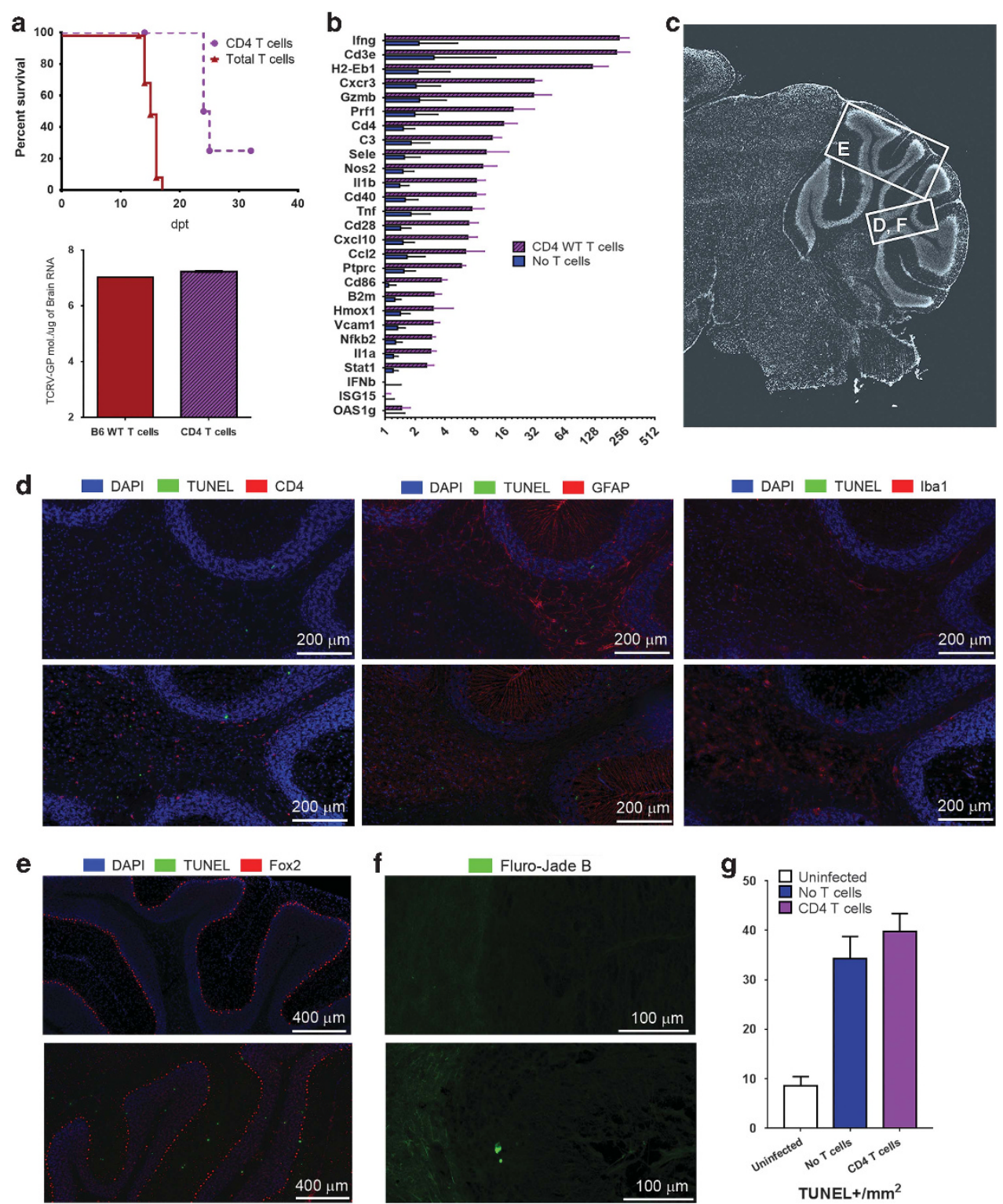

Figure 6 CD4+ T cells are associated with CNS activated microglia but not apoptosis. (a) Survival curve (left) and viral load (right) of CD3e KO mice that received purified CD4+ T cells (circle) or total T cells (squares) from naïve B6 WT mice. Absolute quantification of TCRV-GP transcripts in the CNS of infected B6 WT total and CD4+ T-cell recipients was determined at 15 dpt. (b) Relative gene expression in the CNS of TCRV-infected CD3ع KO mice receiving CD4+ T cells. Data are expressed as mean fold-change over the average of age-matched, infected untransferred CD3KO controls ( $n=6$ per group) and normalized to the house keeping gene, GAPDH. Error bars $=$ s.e.m. (c) Wholecerebellum image (4'6-Diamidino-2-Pheylindole (DAPI)), with boxes indicating location of imaging for $\mathbf{d}-\mathbf{f}$ ). (d-f) Sagittal sections from

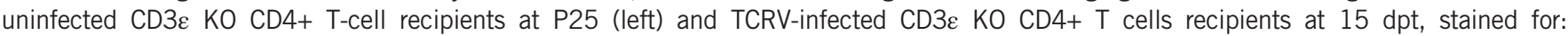
(d) TUNEL+ cells (green), combined with anti-CD4 (T cells); GFAP (astrocytes), or Iba-1 (microglia) staining. Scale bar $=200 \mu \mathrm{m}$. (e) TUNEL + cells (green) and Fox2 (Purkinje cells). Scale bar $=400 \mu \mathrm{m}$. (f) Floro-Jade B stain for degenerative neurons (green). Scale bar $=100 \mu \mathrm{m}$. Images are representative of $N=4$ animals, in two independent experiments. (g) Quantification of TUNEL+ cells. The mean number of cells $/ \mathrm{mm}^{2}$ counted in at least five fields of view per section from at least two mice. Abbreviations: CNS, central nervous system; TCRV, Tacaribe virus; TUNEL, terminal deoxynucleotidyl transferase dUTP nick end labeling; WT, wild type.

the absence of T cells TCRV only elicits a mild inflammatory reaction of the meninges ${ }^{36}$ and the majority of animals live a normal life span. Instead as shown above, TCRV pathogenesis requires antigen-specific $\mathrm{T}$ cells that infiltrate the cerebellar parenchyma, leading to an increase in the expression of inflammatory cytokines and cytolytic proteins as well as activation of glial cells, particularly microglia. Interestingly, although the CNS is predominantly infiltrated by CD8+ T cells, both CD4+ and CD8+ T cells independently drive a lethal encephalitis, albeit via different mechanisms.

CNS infiltration by cytolytic CD8+ $\mathrm{T}$ cells in response to TCRV infection is associated with increased expression of perforin and granzyme B resulting in the apoptosis of astrocytes and a concomitant degeneration of cerebellar neurons, 


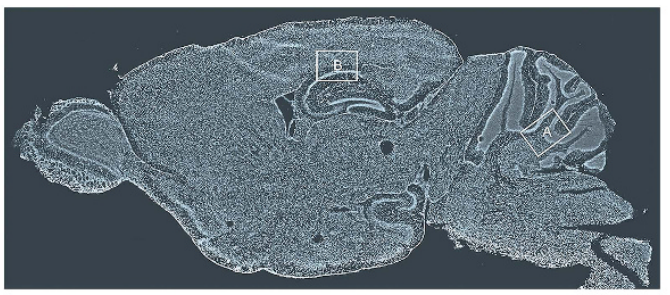

a
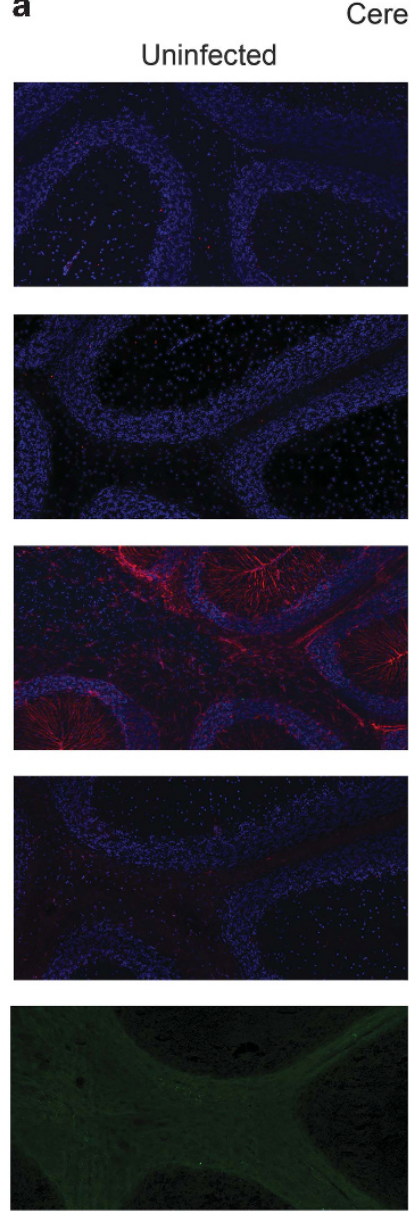

Cerebellum
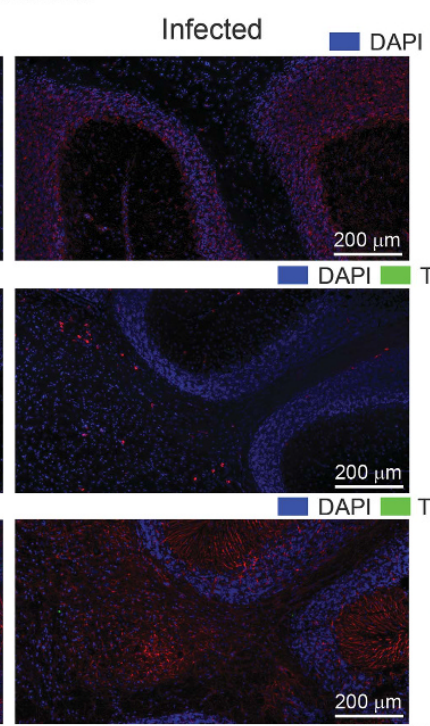

DAPI
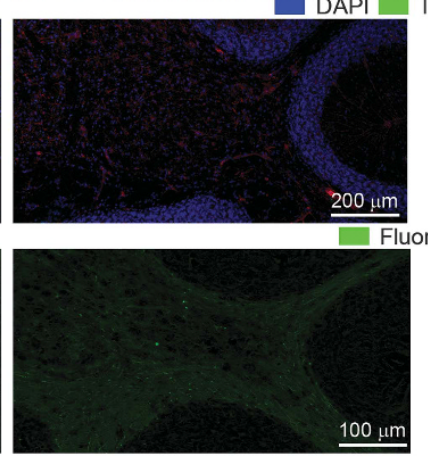

b

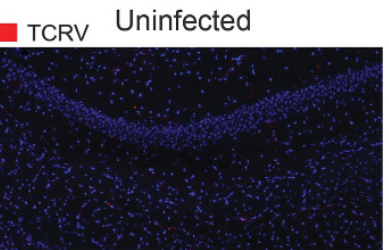

TUNEL $\square$ CD4
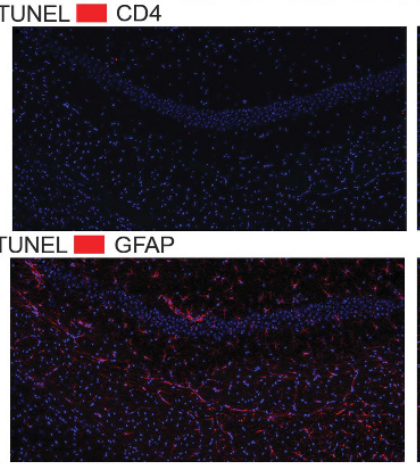

UNEL $\square \mathrm{ba}-1$
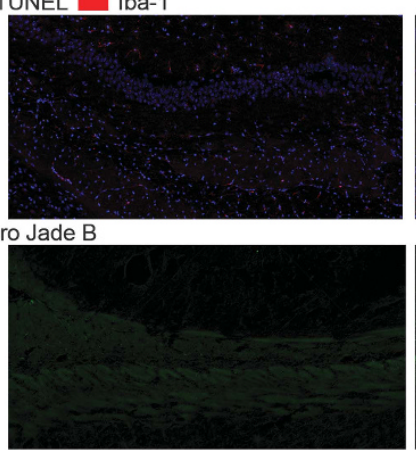

Cortex

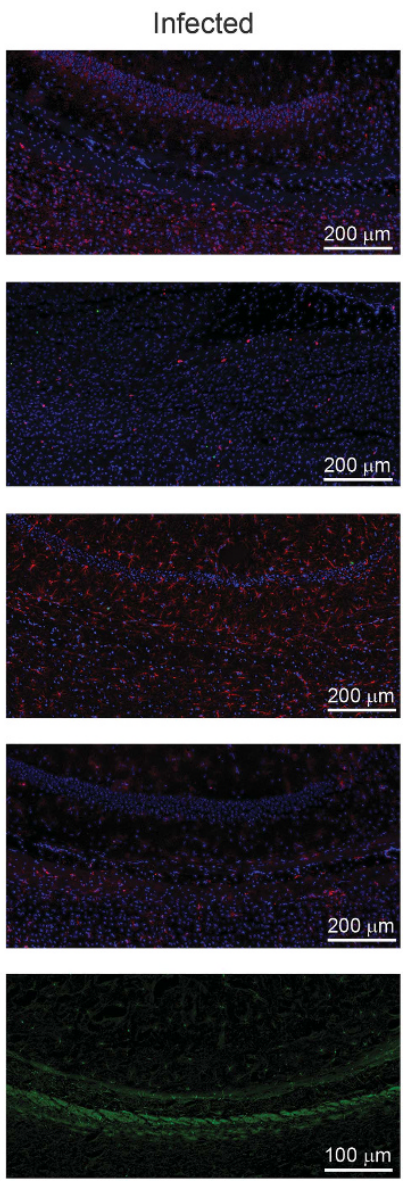

Figure 7 Widespread gliosis and neural disruption but no apoptosis at $28 \mathrm{dpt}$ in mice receiving CD4+ T cells. Top. Sagittal section of CNS (4'6-Diamidino-2-Pheylindole (DAPI)) with boxes indicating location of imaging for the cerebellum (a) and the cerebral cortex (b) IF-IHC compares staining in uninfected, (P35, left) and TCRV-infected (28 dpt, right) CD4+ T cells recipients. Images representative of three mice per group with similar results. IF-IHC was performed as described in Figures 5 and 6 . Scale bar $=200 \mu \mathrm{m}$ for all but Fluoro-Jade B staining, Scale bar $=100 \mu \mathrm{m}$. Abbreviations: CNS, central nervous system; IF-IHC, immunofluorescence immunohistochemistry; TCRV, Tacaribe virus.

with consequent reduction in the number of Purkinje cells and other neurons of the granular layers. In contrast, the same infection in mice bearing only CD4+ $\mathrm{T}$ cells results in higher expression of proinflammatory genes with diffuse increase in Iba-1+ and GFAP+ cells, suggesting gliosis throughout the CNS concomitant with neural degeneration in the absence of increased apoptosis. These results differ from those in the intracerebral model of LCMV infection, where CD4+ T cells, in the absence of CD8+ T cells, induce a non-fatal encephalitis marked by reduced body weight and increase malaise. ${ }^{37,38}$

In the TCRV model used here, intraperitoneal challenge is followed by a transient peripheral infection that is undetectable by $6 \mathrm{dpi}$, after which infectious virus is found exclusively within the $\mathrm{CNS}^{12}$ (unpublished observation), and primarily but not exclusively within GFAP+ cerebellar astrocytes. Importantly, unlike other arenavirus such as LCMV, TCRV resides exclusively in the CNS and does not spread systemically even in severely immunocompromised mice (see Pedras-Vasconcelos et al. $^{39}$ and unpublished observation). While several TCRV receptors that could mediate cell entry have been recently proposed, ${ }^{40,41}$ neither the route by which TCRV enters the CNS nor the factors defining its tropism to the CNS has been defined. Our results showing that persistently infected, yet asymptomatic, adult $\mathrm{CD} 3 \varepsilon \mathrm{KO}$ mice develop acute encephalitis 
and die following a T-cell transfer confirm that $\mathrm{T}$ cells are necessary for pathology. However, the determinants for the selective susceptibility to infection of the neonatal CNS are still unclear. One possibility, as reported for other viruses such as non-neurotropic Sindbis Virus A339, is that infection requires receptors expressed selectively in the immature CNS. ${ }^{42,43}$ However, our studies show that as the disease progresses the virus spreads to infect the cortex and hippocampus and the cells harboring the virus broadens to include neurons (Figure 7). This indicates that the virus can infect fully mature cells in the CNS and the limitation to infecting immature cells is restricted to the initial infection. Alternatively, the increased susceptibility in neonatal mice may be linked to a relatively lower IFN response; however, in our hands adult IFNAR KO mice are not susceptible to peripheral TCRV infection (data not shown). Of note, the virus does not infect $\mathrm{T}$ cells and thus these cells are neither a reservoir for infection nor a vehicle for CNS infection. Further studies will be required to fully understand the selective tropism of TCRV.

The cerebellum is involved not only with balance and posture but also with emotions, language and cognition. In patients, cerebellar pathology has been associated with ataxia as well as autism and schizophrenia. ${ }^{44}$ Further histopathological findings show reduced number of Purkinje cells in subjects with autism. ${ }^{45}$ Our studies and others have shown that TCRV, like Borna disease virus (BDV) and LCMV, infects the cerebellum resulting in neurological sequelae. ${ }^{15,46}$ Interestingly, WT mice infected with TCRV (as well as CD3e KO-infected mice that received $\mathrm{CD} 8+\mathrm{T}$ cells) show reduced number of neurons in the granular layers and loss of PC. This is similar to what was described in BDV-infected rats, but unlike BDV, viral antigen was evident primarily in astrocytes and only rare staining for viral antigen was evident in the neurons. ${ }^{15,46}$ The precise mechanism of virus-induced neuronal loss remains unclear, but the absence of tissue damage in mice lacking $\mathrm{T}$ cells strongly suggests that the virus does not trigger cell death directly or indirectly by depriving growing neurons of trophic factors crucial for survival. Instead, like in LCMV, the immune and inflammatory response to the virus appears to mediate the damage. Of note, the infiltrating $\mathrm{T}$ cells did not localize to the area of missing PC and apoptotic PC were not observed (Figures 2, 4 and 5), suggesting that the reduction in PC may be secondary to changes in the CNS microenvironment that result in neurotoxicity or dysregulation of neuroprotective astrocytes and/or microglia.

$\mathrm{T}$ cells reduce the susceptibility of mice to many CNS viral infections such as measles and West Nile virus; ${ }^{47-51}$ however, T-cell-mediated damage to the CNS has been described in LCMV and BDV. ${ }^{22,46}$ The studies presented here show that TCRV infection in T-cell sufficient animals results in significant infiltration of $\mathrm{T}$ cells and monocytes into the parenchyma of the CNS, while T-cell-deficient mice (CD3e KO) develop only a mild inflammation with marginal increases in the expression of chemokines and proinflammatory cytokines (Figure 3aii). The reconstitution of T-cell populations in $\mathrm{CD} 3 \varepsilon \mathrm{KO}$ animals using naïve WT $\mathrm{T}$ cells, but not OT-1 T cells (Figure 3b), rescued pathology in recipient mice confirming that the pathogenic T cells must be TCRV specific. This is supported by the observed decreased time to disease onset and increased death rate of animals that received $\mathrm{T}$ cells isolated from convalescent WT mice as compared with mice that received naïve T cells (Figure $3 \mathrm{bi}$ ). This is consistent with the presence of an expanded population of virus-specific $\mathrm{T}$ cells in splenocytes isolated from the convalescent animals, whereas a virus-specific response must develop in naïve T-cell donor populations. As expected, however, the pattern of gene expression in the CNS of the infected recipients at the peak of disease (unpublished observation) was similar between naïve and convalescent $\mathrm{T}$-cell recipients, indicating that the memory and naïve $\mathrm{T}$ cells mediate similar pathological changes.

In infected $\mathrm{WT}$ mice and $\mathrm{CD} 3 \varepsilon \mathrm{KO} \mathrm{T}$-cell recipients, activated $\mathrm{CD} 8+\mathrm{T}$ cells were the dominant subtype found in CNS even if there was a $1: 2, \mathrm{CD} 8+: \mathrm{CD} 4+$ ratio in the donor population (Supplementary Figure S2), or a 1:1, CD8+:CD4+ ratio of $\mathrm{T}$ cells in the reconstituted draining cervical lymph nodes (Supplementary Figure S3). These data suggest that as reported in LCMV-infected mice, CD8+ T cells are preferentially attracted to the CNS in response to TCRV infection (Figures 2 and 3d). ${ }^{52}$ However, whereas in LCMV infection the infiltrating $\mathrm{T}$ cells localized to the cerebral-spinal fluid, meninges and periventricular areas of the brain, ${ }^{54,55}$ TCRV infection causes infiltrating $\mathrm{T}$ cells to penetrate all layers of the cerebellum, supporting a direct cytolytic response that underlies the observed tissue damage. Unlike other models of viral encephalitis such as vaccinia or herpes, where CD4+ T cells are required for the activation and maturation of cytolytic CD8+ $\mathrm{T}$ cells ${ }^{56,57}$ with TCRV the transfer of purified CD8+ T cells was sufficient to induce tremors, paralysis and death without significant delay relative to those animals that received both T-cell subsets. These mice showed increased CXCR3, IFNg, Gzmb, Prf1 and TNF in the CNS, consistent with the infiltration of cytolytic effector $\mathrm{T}$ cells and IHC staining showed evidence of apoptosis of astrocytes with concomitant neurodegeneration and loss of PC that was indistinguishable from that of mice that received total $\mathrm{T}$ cells. It is possible that sustained IFN- $\beta$ expression may contribute to CD8+ T-cell function in the absence of T-cell help, ${ }^{58,59}$ as TCRV differs from other arenaviruses in that its NP does not inhibit type I IFN production ${ }^{60}$ and we observe IFN- $\beta$ and interferonstimulated gene expression at $15 \mathrm{dpt}$ of total $\mathrm{T}$ cells (Figure 3biii). Together, these data suggest that CD8+ T cells are the primary effector cell in the fatal encephalitis that follows TCRV infection and their pathogenic role in the CNS is independent of CD4+ T-cell help.

Compared with our understanding of the cytolytic function of $\mathrm{CD} 8+\mathrm{T}$ cells, the pathogenic role of $\mathrm{CD} 4+\mathrm{T}$ cells in neural tropic infections is not as well defined. ${ }^{61,62}$ In LCMV, McGavern et al. ${ }^{63}$ showed T-cell-produced IFN- $\gamma$ is required to recruit monocytes and to activate microglia to the CNS, which leads to increased inflammation and CD4+ T-cellmediated non-fatal wasting disease in the absence of CD8+ T cells. ${ }^{63}$ In TCRV-infected WT mice we showed increased 
expression of $T$-bet and $I F N \gamma$, but not in $I L-17$ or $I L-4$, suggesting that the CD4+ $\mathrm{T}$ cells infiltrating the CNS in response to TCRV belong to the $\mathrm{T}_{\mathrm{H}} 1$ subtype. Further, there was a minimal increase in $I L-10$ and no change in Foxp3 transcripts in the CNS, suggesting that $\mathrm{CD} 4+$ regulatory $\mathrm{T}$ cells $\left(\mathrm{T}_{\text {reg }}\right)$ do not infiltrate the CNS. The absence of $\mathrm{T}_{\text {reg }}$ in TCRVinfected CNS was confirmed using transgenic mice expressing EGFP under the control of the FoxP3 promoter (FoxP3:EGFP; unpublished observation). Infected $\mathrm{CD} 3 \varepsilon \mathrm{KO}$ mice that received purified $\mathrm{CD} 4+\mathrm{T}$ cells showed significant upregulation of genes linked to cytotoxicity (Prf1, Gzmb, IFN $\gamma$ ), activated APC (H2-Eb1, CD86, CD40) and inflammation (C3, Sele, Nos2, $\mathrm{TNFa}, \mathrm{Il}-1 \mathrm{~b})$ that were associated with extensive microgliosis of the cerebellum at $15 \mathrm{dpt}$. Remarkably, despite the increase in markers of inflammation the mice remained asymptomatic until about 1 month post-transfer. Only when the virus had spread to the frontal cortex and hippocampus, showing evidence of extensive astrogliosis and neurodegeneration, did the wasting disease became clinically evident and CD4+ T-cell recipients died. The extensive microglial activation, persistent viral infection and inflammation observed in these mice recalls the pathology observed in other persistent CNS infections, such as patients chronically infected with HIV. ${ }^{64}$ There is an increasing body of work indicating that chronically activated microglia, regulated by CD4+ T cells, can result in neurodegeneration through the chronic secretion of factors such as TNF, NO and IL-1 $\beta^{65,66,67}$ Given the absence of the apoptosis observed when only CD4+ T cells are present in the CNS, it is likely that the observed neurodegeneration in CD4+ T-cell recipients is the result of gliosis mediated cytotoxicity. The precise molecules and mechanisms involved in this CD4+ T-cell-mediated neurodegeneration are currently under investigation.

It is well established that several chemokines including CXCL10 mediate the recruitment of peripheral cells including macrophages to the CNS. Macrophages and microglia are a critical source of TNF. Previous studies had shown that in TCRV or BDV encephalitis, TNF plays a key role in disease pathogenesis and blocking TNF prevented death even in the absence of viral clearance. ${ }^{15,68}$ We show that in the absence of $\mathrm{T}$ cells the expression of chemokines and subsequent macrophage infiltration is significantly reduced and CD45lo microglia do not express detectable levels of MHC class 2, NOS2 or co-stimulatory CD80 and CD86. Further, there is no evidence of microgliosis with Iba-1 staining despite increased expression of CCL2, CCL5 and CXCL10. Thus, in the absence of T cells, TCRV infection is insufficient to attract myeloid cells from the periphery or activate brain-resident APCs in the CNS (Figure 3 and data not shown). ${ }^{63,69,70}$ Therefore, although CD3e KO mice have an intact myeloid compartment it is not possible to discern the relative contribution of macrophages, microglia and cytotoxic $\mathrm{T}$ cells to the disease. Future work using conditional CD11b KO animals will allow us to explore what role, if any, microglia/macrophages play in TCRV encephalitis.

Together, these data show that peripheral challenge with TCRV results in a lethal meningoencephalitis in immunocompetent neonatal mice that is dependent on the infiltration of antigen-specific effector T cells into the CNS. Activated CD4+ and CD8+ $\mathrm{T}$ cells can mediate neurological damage and death independently. CNS infiltration with antigen-specific cytolytic $\mathrm{CD} 8+\mathrm{T}$ cells is associated with apoptosis of GFAP+ astrocytes and loss of granular layer neurons and Purkinje cells in the brain stem and cerebellum. The lethal meningoencephalitis mediated by CD4+ T cells has a slower clinical course and is not associated with apoptosis of the astrocytes. Instead, CD4+ $\mathrm{T}$ cells are associated with a $\mathrm{T}_{\mathrm{H}} 1$ profile and the recruitment and activation of macrophages/microglia resulting in extensive microgliosis. These data demonstrate that developing therapies that modulate T-cell responses to viral infections in the CNS may be critical in attenuating the clinical course and reducing the neurodevelopmental complications associated with some viral encephalitis and attempts to use T cells as immunotherapeutics should be done with caution.

\section{CONFLICT OF INTEREST}

The authors declare no conflict of interest.

\section{ACKNOWLEDGEMENTS}

We thank Jill Ascher, Mary Belcher and the personnel of the animal facility for care of the mice. We thank Dr Cherie Butts, Dr Gouri Chattopadhyay, John Martucci and Vivian Wang for technical assistance and Dr Mohanraj Manageeswaran for helpful discussions. We also thank Drs Steven Rubin and Christian Sauder for careful review of the manuscript. This study was supported in part by a Senior Postgraduate Research Fellowship Award to DI from the Oak Ridge Institute for Science and Education (ORISE) through an interagency agreement between the U.S. Department of Energy and the U.S. Food and Drug Administration. This study was also supported by a grant from the FDA Medical Countermeasures Initiative program to DV.

1 Bowen M, Peters CJ, Nichol ST. The phylogeny of New World (Tacaribe complex) arenaviruses. Virology 1996; 219: 285-290.

2 Salvato MS, Charrel RN, Clegg JCS, Buchmeier MJ, Gonzalez JP, Lukashevich IS et al. Family arenaviridae. In: Regenmortel MHV, van Fauquet CM, Bishop CM (eds). Virus Taxonomy, 8th edn. Academic Press: Orlando. 2004, pp 633-640.

3 Martinez-Peralta LA, Coto CE, Weissenbacher MC. The Tacaribe complex - the close relationship between a pathogenic (Junin) and a nonpathogenic (Tacaribe) arenavirus. In: Salvato M (ed.). The Arenaviridae, 1st edn. Plenun Press: New York, 1993, pp 281-298.

4 Enria DA, Briggiler AM, Sanchez Z. Treatment of Argentine hemorrhagic fever. Antiviral Res 2008; 78: 132-139.

5 Charrel RN, de Lamballerie X. Arenaviruses other than Lassa virus. Antiviral Res 2003; 57: 89-100.

6 Pedras-Vasconcelos JA, Goucher D, Puig M, Tonelli LH, Wang V, Ito S et al. CpG oligodeoxynucleotides protect newborn mice from a lethal challenge with the neurotropic Tacaribe arenavirus. J Immunol 2006; 176: 4940-4949.

7 Zeitlin L, Geisbert JB, Deer DJ, Fenton KA, Bohorov O, Bohorova N et al. Monoclonal antibody therapy for Junin virus infection. Proc Natl Acad Sci USA 2016; 113: 4458-4463.

8 Ghiringhelli PD, Rivera-Pomar RV, Lozano ME, Grau O, Romanowski V. Molecular organization of Junin virus S RNA: complete nucleotide sequence, relationship with other members of the Arenaviridae and unusual secondary structures. J Gen Virol 1991; 72: 2129-2141. 
9 Coto CE, Damonte EB, Catello MA, Weissenbacher MC. Protection of guinea pigs inoculated with Tacaribe virus against lethal doses of Junin virus. J Infect Dis 1980; 141: 389-393.

10 Weissenbacher MC, Coto CE, Calello MA. Cross-protection between Tacaribe complex viruses. Presence of neutralizing antibodies against Junin virus (Argentine hemorrhagic fever) in guinea pigs infected with Tacaribe virus. Intervirology 1975; 6: 42-49.

11 Borden EC, Nathanson N. Tacaribe virus infection of the mouse: an immunopathologic disease model. Lab Invest 1974; 30: 465-473.

12 Pedras-Vasconcelos JA, Goucher D, Puig M, Tonelli LH, Wang V, Ito S et al. CpG oligodeoxynucleotides protect newborn mice from a lethal challenge with the neurotropic Tacaribe arenavirus. J Immunol 2006; 176: 4940-4949.

13 Ayerra de Holstein BL, Teyssie AR, Knecher LN, Samoilovish SR, Coto CE, Weissebacher M. Induccion de Interferon por el virus Tacaribe. Medicina 1981; 41: 177-181.

14 Parodi AS, Schmunis GA, Weissenbacher MC. Infection with viruses of the Tacaribe group in thymectomized mice. Experientia 1970; 26 665-666.

15 Pedras-Vasconcelos JA, Puig M, Sauder C, Wolbert C, Ovanesov M, Goucher $\mathrm{D}$ et al. Immunotherapy with $\mathrm{CpG}$ oligonucleotides and antibodies to TNF-alpha rescues neonatal mice from lethal arenavirus-induced meningoencephalitis. J Immunol 2008; 180: 8231-8240.

16 Herz J, Johnson KR, McGavern DB. Therapeutic antiviral T cells noncytopathically clear persistently infected microglia after conversion into antigen-presenting cells. J Exp Med 2015; 212: 1153-1169.

17 Malissen M, Gillet A, Ardouin L, Bouvier G, Trucy J, Ferrier P et al. Altered $T$ cell development in mice with a targeted mutation of the CD3-epsilon gene. EMBO J 1995; 14: 4641-4653.

18 Grajkowska LT, Pedras-Vasconcelos JA, Sauder C, Verthelyi D, Puig M. High-throughput real-time PCR for early detection and quantitation of arenavirus Tacaribe. J Virol Methods 2009; 159: 239-243.

19 Livak KJ, Schmittgen TD. Analysis of relative gene expression data using real-time quantitative PCR and the 2-[Delta][Delta]CT method. Methods 2001; 25: 402-408.

20 Schmued LC, Hopkins KJ, Fluoro-Jade B. a high affinity fluorescent marker for the localization of neuronal degeneration. Brain Res 2000; 874: 123-130.

21 Schindelin J, Arganda-Carreras I, Frise E, Kaynig V, Longair M, Pietzsch T et al. Fiji: an open-source platform for biological-image analysis. Nat Methods 2012; 9: 676-682.

22 Kim KK, Kim YC, Adelstein RS, Kawamoto S. Fox-3 and PSF interact to activate neural cell-specific alternative splicing. Nucleic Acids Res 2011; 39: 3064-3078.

23 Loughlin AJ, Woodroofe MN, Cuzner ML. Regulation of Fc receptor and major histocompatibility complex antigen expression on isolated rat microglia by tumour necrosis factor, interleukin-1 and lipopolysaccharide: effects on interferon-gamma induced activation. Immunology 1992; 75: 170-175.

24 Sporici R, Issekutz TB. CXCR3 blockade inhibits T-cell migration into the CNS during EAE and prevents development of adoptively transferred, but not actively induced, disease. Eur J Immunol 2010; 40: 2751-2761.

25 Christensen JE, Nansen A, Moos T, Lu B, Gerard C, Christensen JP et al. Efficient T-cell surveillance of the CNS requires expression of the CXC chemokine receptor 3. J Neurosci 2004; 24: 4849-4858.

26 Crain JM, Nikodemova M, Watters JJ. Microglia express distinct M1 and $\mathrm{M} 2$ phenotypic markers in the postnatal and adult central nervous system in male and female mice. J Neurosci Res 2013; 91: 1143-1151.

27 Sierra-Filardi E, Vega MA, Sanchez-Mateos P, Corbi AL, Puig-Kroger A. Heme oxygenase-1 expression in M-CSF-polarized M2 macrophages contributes to LPS-induced IL-10 release. Immunobiology 2010; 215: 788-795.

28 Swain SL, McKinstry KK, Strutt TM. Expanding roles for CD4(+) $T$ cells in immunity to viruses. Nat Rev Immunol 2012; 12: $136-148$.

29 Louveau A, Smirnov I, Keyes TJ, Eccles JD, Rouhani SJ, Peske JD et al. Structural and functional features of central nervous system lymphatic vessels. Nature 2015; 523: 337-341.

30 Li F, Wang Y, Yu L, Cao S, Wang K, Yuan J et al. Viral infection of the central nervous system and neuroinflammation precede blood-brain barrier disruption during Japanese encephalitis virus infection. J Virol 2015; 89: 5602-5614.

31 Johnson HL, Chen Y, Suidan GL, McDole JR, Lohrey AK, Hanson LM et al. A hematopoietic contribution to microhemorrhage formation during antiviral CD8 T cell-initiated blood-brain barrier disruption. J Neuroinflammation 2012; 9: 60.

32 Engelhardt B, Ransohoff RM. Capture, crawl, cross: the T cell code to breach the blood-brain barriers. Trends Immunol 2012; 33: 579-589.

33 Pender MP, Burrows SR. Epstein-Barr virus and multiple sclerosis: potential opportunities for immunotherapy. Clin Trans/ Immunol 2014; 3: e27.

34 Riddell SR, Watanabe KS, Goodrich JM, Li CR, Agha ME, Greenberg PD. Restoration of viral immunity in immunodeficient humans by the adoptive transfer of T cell clones. Science 1992; 257: 238-241.

35 Kerschensteiner M, Meinl E, Hohlfeld R. Neuro-immune crosstalk in CNS diseases. Neuroscience 2009; 158: 1122-1132.

36 Moseman EA, McGavern DB. The great balancing act: regulation and fate of antiviral T-cell interactions. Immunol Rev 2013; 255: 110-124.

37 Fung-Leung WP, Kundig TM, Zinkernagel RM, Mak TW. Immune response against lymphocytic choriomeningitis virus infection in mice without CD8 expression. J Exp Med 1991; 174: 1425-1429.

38 Kamperschroer C, Quinn DG. The role of proinflammatory cytokines in wasting disease during lymphocytic choriomeningitis virus infection. J Immunol 2002; 169: 340-349.

39 Pedras-Vasconcelos JA, Puig M, Sauder C, Wolbert C, Ovanesov M, Goucher $\mathrm{D}$ et al. Immunotherapy with $\mathrm{CpG}$ oligonucleotides and antibodies to TNF-alpha rescues neonatal mice from lethal arenavirus-induced meningoencephalitis. J Immunol 2008; 180 : $8231-8240$.

40 Roldan JS, Martinez MG, Forlenza MB, Whittaker GR, Candurra NA. Human transferrin receptor triggers an alternative Tacaribe virus internalization pathway. Arch Virol 2015.

41 Jemielity S, Wang JJ, Chan YK, Ahmed AA, Li W, Monahan S et al. TIM-family proteins promote infection of multiple enveloped viruses through virion-associated phosphatidylserine. PLoS Pathog 2013; 9: e1003232.

42 Stanley J, Cooper SJ, Griffin DE. Alphavirus neurovirulence: monoclonal antibodies discriminating wild-type from neuroadapted Sindbis virus. J Virol 1985; 56: 110-119.

43 Lustig S, Jackson AC, Hahn CS, Griffin DE, Strauss EG, Strauss JH. Molecular basis of Sindbis virus neurovirulence in mice. J Virol 1988; 62: 2329-2336.

44 Shi L, Smith SEP, Malkova N, Tse D, Su Y, Patterson PH. Activation of the maternal immune system alters cerebellar development in the offspring. Brain Behav Immun 2009; 23: 116-123.

45 Palmen SJMC, van Engeland H, Hof PR, Schmitz C. Neuropathological findings in autism. Brain 2004; 127: 2572-2583.

46 Pletnikov MV, Rubin SA, Moran TH, Carbone KM. Exploring the cerebellum with a new tool: neonatal Borna disease virus (BDV) infection of the rat's brain. Cerebellum 2003; 2: 62-70.

47 Purtha WE, Myers N, Mitaksov V, Sitati E, Connolly J, Fremont DH et al. Antigen-specific cytotoxic $T$ lymphocytes protect against lethal West Nile virus encephalitis. Eur J Immunol 2007; 37: 1845-1854.

48 Shrestha B, Pinto AK, Green S, Bosch I, Diamond MS. CD8+ T cells use TRAIL to restrict West Nile virus pathogenesis by controlling infection in neurons. J Virol 2012; 86: 8937-8948.

49 Stubblefield Park SR, Widness M, Levine AD, Patterson CE. T cell-, interleukin-12-, and gamma interferon-driven viral clearance in measles virus-infected brain tissue. J Virol 2011; 85: 3664-3676.

50 Patterson CE, Lawrence DM, Echols LA, Rall GF. Immune-mediated protection from measles virus-induced central nervous system disease is noncytolytic and gamma interferon dependent. J Virol 2002; 76: 4497-4506.

51 Reuter D, Schneider-Schaulies J. Measles virus infection of the CNS: human disease, animal models, and approaches to therapy. Med Microbiol Immunol 2010; 199: 261-271.

52 Cole GA, Nathanson N, Prendergast RA. Requirement for theta-bearing cells in lymphocytic choriomeningitis virus-induced central nervous system disease. Nature 1972; 238: 335-337.

53 Doherty PC, Allan JE, Lynch F, Ceredig R. Dissection of an inflammatory process induced by CD8+ T cells. Immunol Today 1990; 11: 55-59.

54 Buchmeier MJ, Welsh RM, Dutko FJ, Oldstone MB. The virology and immunobiology of lymphocytic choriomeningitis virus infection. Adv Immunol 1980; 30: 275-331. 
55 Ceredig R, Allan JE, Tabi Z, Lynch F, Doherty PC. Phenotypic analysis of the inflammatory exudate in murine lymphocytic choriomeningitis. J Exp Med 1987; 165: 1539-1551.

56 Novy P, Quigley M, Huang X, Yang Y. CD4 T cells are required for CD8 $T$ cell survival during both primary and memory recall responses. $\mathrm{J}$ Immunol 2007; 179: 8243-8251.

57 Smith CM, Wilson NS, Waithman J, Villadangos JA, Carbone FR, Heath WR et al. Cognate CD4(+) T cell licensing of dendritic cells in CD8(+) T cell immunity. Nat Immunol 2004; 5: 1143-1148.

58 Kolumam GA, Thomas S, Thompson LJ, Sprent J, Murali-Krishna K. Type I interferons act directly on CD8 T cells to allow clonal expansion and memory formation in response to viral infection. J Exp Med 2005; 202: 637-650.

59 Wiesel M, Kratky W, Oxenius A, Type I. IFN substitutes for T cell help during viral infections. J Immunol 2011; 186: 754-763.

60 Martinez-Sobrido L, Giannakas P, Cubitt B, Garcia-Sastre A, de la Torre JC. Differential inhibition of type I interferon induction by arenavirus nucleoproteins. J Virol 2007; 81: 12696-12703.

61 Stohlman SA, Hinton DR, Parra B, Atkinson R, Bergmann CC. CD4 T cells contribute to virus control and pathology following central nervous system infection with neurotropic mouse hepatitis virus. J Virol 2008; 82: 2130-2139.

62 Palma JP, Yauch RL, Lang S, Kim BS. Potential role of CD4+ $T$ cell-mediated apoptosis of activated astrocytes in Theiler's virusinduced demyelination. J Immunol 1999; 162: 6543-6551.

63 Lin AA, Tripathi PK, Sholl A, Jordan MB, Hildeman DA. Gamma interferon signaling in macrophage lineage cells regulates central nervous system inflammation and chemokine production. J Virol 2009; 83: 8604-8615.

64 Suh J, Sinclair E, Peterson J, Lee E, Kyriakides TC, Li FY et al. Progressive increase in central nervous system immune activation in untreated primary HIV-1 infection. J Neuroinflammation 2014; 11: 199.

65 Lull ME, Block ML. Microglial activation and chronic neurodegeneration. Neurotherapeutics 2010; 7: 354-365.
66 Gonzalez H, Contreras F, Pacheco R. Regulation of the neurodegenerative process associated to Parkinson's disease by CD4+ T-cells. J Neuroimmune Pharmacol 2015; 10: 561-575.

67 Gonzalez H, Pacheco R. T-cell-mediated regulation of neuroinflammation involved in neurodegenerative diseases. J Neuroinflammation 2014; 11: 201.

68 Kramer K, Schaudien D, Eisel UL, Herzog S, Richt JA, Baumgartner W et al. TNF-overexpression in Borna disease virus-infected mouse brains triggers inflammatory reaction and epileptic seizures. PLoS One 2012; 7: e41476.

69 Christensen JE, Simonsen S, Fenger C, Sorensen MR, Moos T, Christensen JP et al. Fulminant lymphocytic choriomeningitis virus-induced inflammation of the CNS involves a cytokinechemokine-cytokine-chemokine cascade. J Immunol 2009; 182: 1079-1087.

70 McKimmie CS, Graham GJ. Astrocytes modulate the chemokine network in a pathogen-specific manner. Biochem Biophys Res Commun 2010; 394: 1006-1011.

(c) (1) () $\Theta$ This work is licensed under a Creative Commons Attribution-NonCommercial-NoDerivs 4.0 International License. The images or other third party material in this article are included in the article's Creative Commons license, unless indicated otherwise in the credit line; if the material is not included under the Creative Commons license, users will need to obtain permission from the license holder to reproduce the material. To view a copy of this license, visit http://creativecommons.org/licenses/by-nc-nd/4.0/

(C) The Author(s) 2017

Supplementary Information for this article can be found on the Cellular \& Molecular Immunology website (http://www.nature.com/cmi) 